\title{
The Role of Nrf2 in Cardiovascular Function and Disease
}

\author{
Sandro Satta, ${ }^{1}$ Ayman M. Mahmoud, ${ }^{2}$ Fiona L. Wilkinson, ${ }^{1}$ M. Yvonne Alexander, ${ }^{1}$ and \\ Stephen J. White ${ }^{1}$ \\ ${ }^{1}$ Vascular Pathology Group, Centre for Biomedicine, School of Healthcare Science, Manchester Metropolitan University, \\ Manchester M1 5GD, UK \\ ${ }^{2}$ Physiology Division, Zoology Department, Faculty of Science, Beni-Suef University, Beni-Suef 62514, Egypt
}

Correspondence should be addressed to Stephen J. White; stephen.white@mmu.ac.uk

Received 23 May 2017; Accepted 27 July 2017; Published 14 September 2017

Academic Editor: Silvana Hrelia

Copyright (C) 2017 Sandro Satta et al. This is an open access article distributed under the Creative Commons Attribution License, which permits unrestricted use, distribution, and reproduction in any medium, provided the original work is properly cited.

Free radicals, reactive oxygen/nitrogen species (ROS/RNS), hydrogen sulphide, and hydrogen peroxide play an important role in both intracellular and intercellular signaling; however, their production and quenching need to be closely regulated to prevent cellular damage. An imbalance, due to exogenous sources of free radicals and chronic upregulation of endogenous production, contributes to many pathological conditions including cardiovascular disease and also more general processes involved in aging. Nuclear factor erythroid 2-like 2 (NFE2L2; commonly known as Nrf2) is a transcription factor that plays a major role in the dynamic regulation of a network of antioxidant and cytoprotective genes, through binding to and activating expression of promoters containing the antioxidant response element (ARE). Nrf2 activity is regulated by many mechanisms, suggesting that tight control is necessary for normal cell function and both hypoactivation and hyperactivation of Nrf2 are indicated in playing a role in different aspects of cardiovascular disease. Targeted activation of Nrf2 or downstream genes may prove to be a useful avenue in developing therapeutics to reduce the impact of cardiovascular disease. We will review the current status of Nrf2 and related signaling in cardiovascular disease and its relevance to current and potential treatment strategies.

\section{Introduction}

The vascular endothelium modulates vascular structure, thrombolysis, vasoconstriction, and vasodilation and maintains internal homeostasis through synthesizing and releasing several active biomolecules [1]. A loss of function of the endothelium represents a key risk factor for cardiovascular disease (CVD) and initiates the development of atherosclerosis [2]. Endothelial dysfunction is associated with functional changes that diminish nitric oxide (NO) bioavailability and consequently leads to CVD [1]. Sustained failure to counteract the excessive production of reactive oxygen species (ROS) and dysregulation of the antioxidant defence system in the endothelium elicits cellular damage and dysfunction [2]. However, the original concept that all free radicals are damaging disease-causing entities have, over recent years, been replaced by an understanding of the important signaling role they play within and between cells. The production and control of free radicals need to be tightly regulated to prevent cytotoxicity, and the imbalance, caused by exogenous sources of free radicals with chronic upregulation and endogenous production, contributes to many pathological conditions and also to more general processes involved in aging [3-5]. There are multiple cellular defence strategies to prevent free radical toxicity, which are dynamically regulated to protect from oxidative insults and preserve cell function [6]. Nuclear factor erythroid 2-like 2 (NFE2L2; commonly known as Nrf2 [7]) has been identified as a major regulator of the oxidant/antioxidant balance.

The Nrf2 was first discovered in 1994 by Moi et al. during studies on regulation of the $\beta$-globin gene [7]. It was subsequently identified to be profoundly involved in the regulation of oxidant and antioxidant gene expression, through binding to the antioxidant response element (ARE) $[8,9]$. Nrf2/ARE signaling is highly conserved in all species and controls a wide panel of genes that include cytoprotective and detoxifying phase II enzymes [10]. Nrf2 coordinates the cellular response to oxidative insults, preventing damage to cellular 

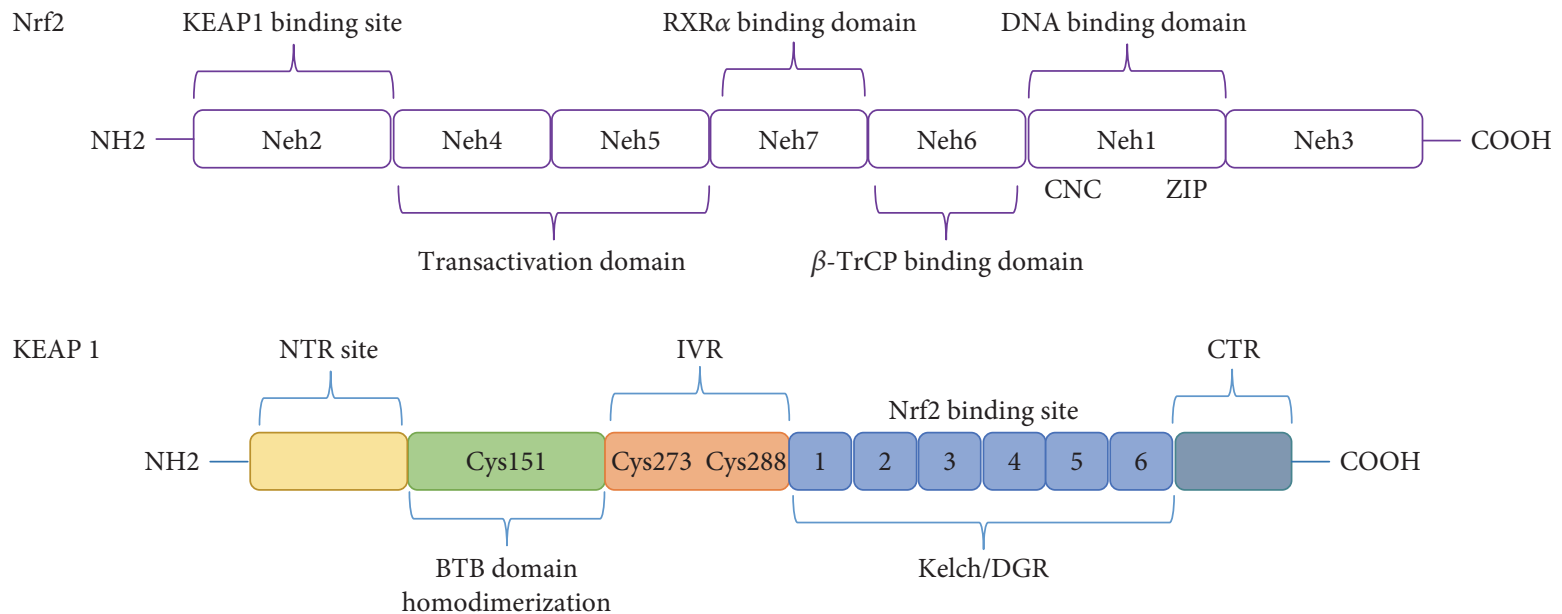

FIGURE 1: Nrf2 and KEAP1 structure. Nrf2 is a cap'n'collar-basic region leucine zipper (CNC-bZIP), and its human sequence contains 605 amino acids, divided into seven domains: Neh1 to Neh7. Neh1 contains a CNC-bZIP motif, allowing heterodimerization with Maf proteins and DNA binding [54]. The Neh2 domain contains the Keap1 binding site (DLG and ETGE motifs), necessary for its cytoplasmic retention and degradation [55]. The Neh3 domain is fundamental for Nrf2 transcriptional activation through binding with chromoATPase/helicase DNA-binding protein 6 (CHD6) [56]. Neh4 and Neh5 provide an interaction site for nuclear cofactor RAC3/AIB1/SRC-3 [57] and CREB-binding protein (CBP) [58] which enhances the Nrf2/ARE activation pathways, partially by promoting acetylation of Nrf2 [59]. Additionally, Nrf2 possesses a redox-sensitive nuclear exporting signal within the Neh5 transactivation domain able to regulate its cellular localization [60]. The serine-rich Neh6 domain contains two motifs (DSGIS and DSAPGS) involved in the negative regulation of Nrf2. Glycogen synthase kinase 3 (GSK-3) phosphorylates serine residues within Neh6 enabling the interaction with the $\beta$-transducin repeat-containing protein $(\beta$-TrCP) which acts as a substrate receptor for Skp1-Cul1-Rbx1/Roc1 ubiquitin ligase complex, leading to KEAP1-independent degradation [41]. Neh7 domain interacts with retinoid X receptor alpha (RXR $\alpha$ ), responsible for Nrf2/ARE signaling inhibition [61]. Human Kelch-like ECH-associated protein 1 (KEAP1) is a $69 \mathrm{kD}$ protein, containing 27 cysteine residues. It is a substrate adaptor for cullin (Cul3) which contains E3 ubiquitin ligase (E3). KEAP1 is composed of five domains starting from the N-terminal region, a BTB dimerization domain (Broad-Complex, Tramtrack, and Bric-à-brac) which contains the Cys151 residue, a cysteine-rich intervening region (IVR) domain with two cysteine domain residues Cys273 and Cys288, critical for stress sensing. A Kelch domain/ double glycine repeat (DGR) domain possessing 6 Kelch repeats and ending with a C-terminal region [62]. KEAP1 needs a domain capable to homodimerize and interact with Cul3, forming the Nrf2 inhibitor complex (iNrf2), and this is the BTB domain [63]. The Cys151 in the same domain plays an important role on Nrf2 activation in response to oxidative stress [64]. Furthermore, the IVR domain is highly sensitive to oxidation and contains three cysteines, 273, 288, and 297 which regulate Nrf2 activation and repression [16, 65]. The DGR domain acts as an Nrf2 repressor; it contains six repetitive Kelch structures that specifically bind to the Neh2 domain on Nrf2 [15].

components sensitive to redox changes (i.e., proteins, lipids, and DNA).

\section{Regulation of Nrf2 Activity}

Nrf2 activity is highly regulated, suggesting that either hypoactivation or hyperactivation of Nrf2 may be detrimental to the cell, for example, unrestricted Nrf2 activity, elicited by knockout of Kelch-like ECH-associated protein 1 (KEAP1) in the mouse, results in postnatal lethality [11], while Nrf2 knockouts are viable but hypersensitive to oxidative stressors. The regulation of Nrf2 has been extensively reviewed elsewhere [12-14] but is briefly summarized here and in Figure 1 and Table 1. Nrf2-regulated gene expression is primarily controlled by KEAP1. In a situation without oxidative stimuli, Nrf2 is mostly sequestered in the cytosol through binding to the Kelch domain of KEAP1 [15]. KEAP1 acts as an adapter molecule for CUL-E3 ligase and mediates the ubiquitination and degradation of Nrf2 protein. Exposure of oxidative/electrophilic stress causes a modification of the cysteine groups on KEAP1 (particularly C151), relaxing the structure of KEAP1 causing dissociation of KEAP1 from CUL-E3 ligase [16-18]. It is unclear if Nrf2 protein dissociates from KEAP1 or if modification of C151 simply blocks further processing of Nrf2 [18]. De novo synthesized $\mathrm{Nrf2}$, or protein released from KEAP1, is then free to translocate to the nucleus. In addition, p21, p62, and the tumor suppressor WTX also potentiate Nrf2 activation through sequestration of KEAP1 or binding to Nrf2 to prevent association with KEAP1 [19-21]. Upon entry into the nucleus, Nrf2 heterodimerizes with a number of transcription factors, including small Maf proteins (allowing formation of full basic zipper, summarized in Figure 1 and Table 1), and binds to the ARE (core sequence RTGACnnnGCA) to induce gene transcription $[22,23]$.

Dissociation of KEAP1 from the CUL-E3 ligase complex can be induced by a large range of compounds, including oxidized phospholipids [24], nitric oxide (NO), zinc, alkenals [25], and cigarette smoke, or fresh aqueous extracts of cigarette smoke [26-28]. However, not all forms of ROS appear to be able to modify KEAP-1/Nrf2 interactions, with data suggesting this is both cell type and context specific. Of particular relevance to CVD, laminar shear stress causes the activation of Nrf2 in endothelial cells [29], through lipid peroxide and COX2-derived 15-deoxy-12,14-prostaglandin J2 (15d-PGJ2) intermediates, enhanced by phosphoinositol 
TABLE 1: List of proteins that bind to and modulate the activity of Nrf2.

\begin{tabular}{|c|c|c|}
\hline Gene & Function & Reference \\
\hline KEAP1 & Retention in cytoplasm and degradation & {$[15]$} \\
\hline CDH1/CTNNB1 & Enhances KEAP1 interaction & {$[66]$} \\
\hline CRF1 & Ubiquitination and degradation & {$[67]$} \\
\hline ATF4 & Activation of gene expression & {$[68]$} \\
\hline BRG1 & Selective activation of gene expression & [69] \\
\hline СBP & Activation of gene expression & {$[58]$} \\
\hline CHD6 & Activation of gene expression & {$[56]$} \\
\hline JUN & Activation of gene expression & [9] \\
\hline MAFF & Heterodimer activates gene expression & {$[70]$} \\
\hline MAFG & Heterodimer activates gene expression & {$[71]$} \\
\hline MAFK & Heterodimer activates gene expression & {$[71]$} \\
\hline PMF1 & Activation of gene expression & {$[72]$} \\
\hline RAC3/AIB1/SRC-3 & Activation of gene expression & [57] \\
\hline $\mathrm{PKC}$ & Phosphorylation increases nuclear translocation & {$[73,74]$} \\
\hline HDAC1/2/3 & Repression of gene expression & {$[75]$} \\
\hline MYC & Repression of gene expression & {$[76]$} \\
\hline PPARG & Repression of gene expression & [77] \\
\hline $\mathrm{RXR} \alpha$ & Repression of gene expression & {$[61]$} \\
\hline FYN & Phosphorylation and nuclear export & {$[52]$} \\
\hline SRC & Phosphorylation and nuclear export & {$[53]$} \\
\hline YES & Phosphorylation and nuclear export & {$[53]$} \\
\hline
\end{tabular}

3-kinase/Akt signaling, but is surprisingly independent of endothelial nitric oxide synthase (eNOS) activity [30-33]. In addition, laminar shear stress increases the nuclear localization of Nrf2 via a KLF2-dependent mechanism [34]. Finally, tumor necrosis factor alpha (TNF- $\alpha$ ) increases the activation of Nrf2 in human endothelial cells [28] and monocytes [35]. A number of naturally occurring compounds have been shown to release Nrf2 from KEAP1 [36], for example, sulforaphane [37], sulfuretin [38], 2-trifluoromethyl-2-methoxychalone [39], and isoliquiritigenin [40], suggesting that dietary modulation of ARE-dependent gene expression could play a potential role in modulating disease.

\section{Additional Regulatory Systems}

In addition to KEAP1-mediated sequestration and degradation of Nrf2 within the cytoplasm, there are a number of additional layers of regulation on Nrf2-dependent gene expression. Degradation of $\mathrm{Nrf} 2$ can also be induced by $\beta$-TrCP-Skp1-Cul1-Rbx1 E3 ubiquitin ligase complex $[41,42]$, triggered by phosphorylation of Nrf2 within the Neh2 domain. Subsequently, the E3 ligase complex ubiquitinates Nrf2 and causes its destruction by the proteasome. Mitra et al. also observed that the inhibition of P38 mitogen-activated protein kinase (MAPK) highly decreased Nrf2 nuclear translocation, with a corresponding reduction of Nrf2-dependent gene expression [43]. While the majority of KEAP1 is normally present in the cytoplasm, $10-15 \%$ has localized to the nucleus [44]; prothymosin-alpha (ProT $\alpha$ ) binds KEAP1, shuttling it into the nucleus, where it can bind
Nrf2 and promote its degradation [45]. Within the nucleus, $\mathrm{B}$-zip proteins $\mathrm{BACH} 1$ and $\mathrm{BACH} 2$ can form dimers with Maf proteins through their BTB domain and compete for binding to the ARE, preventing Nrf2 binding and activation of transcription [46-48]. BACH1 is universally expressed, while $\mathrm{BACH} 2$ expression is predominantly limited to monocytes and in neural cells. Phosphorylation of BACH1 on Y486 provokes nuclear export of BACH1 increasing Nrf2-dependent gene expression $[49,50]$. Nuclear export of Nrf2 is controlled through a GSK- $3 \beta$-controlled phosphorylation cascade. GSK-3 $\beta$ phosphorylates Src family kinases (Src, YES, and Fyn), in turn phosphorylating Nrf2 on Y568 triggering nuclear export and degradation [51-53].

\section{Nrf2 and Mitochondrial Dynamics in Cardiovascular Disease}

Cardiovascular disease is the main cause of death worldwide [78], and it covers a wide array of disorders. The most common causes of CVD morbidity and mortality are stroke, ischemic heart disease (IHD), and congestive heart failure $(\mathrm{CHF})$. Several risk profiles are involved in CVD where ROS is a central mediator and a common denominator, upregulated by multiple risk factors such as diabetes, inflammation, and smoking [79-81]. ROS can cause EC apoptosis and activate nuclear factor kappa-B $(\mathrm{NF}-\kappa \mathrm{B})$, increasing adhesion molecules and cytokines that enhance monocyte adhesion [82, 83]. Oxidative stress is involved in mitochondrial dysfunction, which is related to bioenergetic defects and an alteration in mitochondrial dynamics. This provokes 


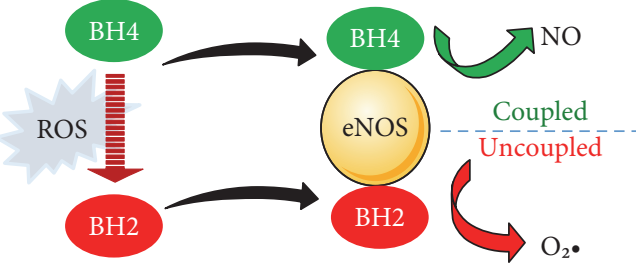

FIGURE 2: ROS-induced uncoupling of eNOS and the generation of $\mathrm{O}_{2} \bullet$. Excess ROS induce the conversion of $\mathrm{BH} 4$ to $\mathrm{BH} 2$ with subsequent eNOS uncoupling and synthesis of $\mathrm{O}_{2} \bullet$ instead of NO. eNOS: endothelial nitric oxide synthase; ROS: reactive oxygen species; $\mathrm{NO}$ : nitric oxide; $\mathrm{O}_{2} \bullet$ : superoxide; $\mathrm{BH} 4$ : tetrahydrobiopterin; $\mathrm{BH} 2$ : dihydrobiopterin.

transcription impairment and cell damage. Blockage of the mitochondrial electron transfer in complex III in diabetes leads to the release of electrons which reduce molecular oxygen to superoxide $\left(\mathrm{O}_{2} \bullet\right)$ and increases intracellular ROS production [84]. Furthermore, ROS can activate membrane oxidases with a subsequent increase in the levels of asymmetric dimethylarginine that competes for the L-arginine transporters and active sites on eNOS [85]. Nrf2 modulates the activity of the mitochondrial respiration chain [86], with pharmacological activation of Nrf2 protecting against toxicity and maintaining mitochondrial homeostasis possibly via ablation of Akt2 signaling [87]. Liu and colleagues discovered acrolein, a component of cigarette combustion, inactivated the KEAP1/Nrf2 pathway, and decreased mitochondrial membrane potential [88], while Zou et al. demonstrated the ability of Nrf2 to prevent mitochondrial dysfunction, using hydroxytyrosol to activate Nrf2 [89].

\section{Nrf2 in Endothelial Dysfunction}

The vascular endothelium modulates vascular homeostasis through synthesizing and releasing several active biomolecules [1]. A loss of endothelium integrity represents a key risk factor for CVD, initiating atherosclerosis [2] and is associated with functional changes that diminish NO bioavailability and, consequently, lead to CVD [1]. Hypoxia, flow disturbances, and oxidative stress are important contributors to endothelial dysfunction [90]. Failure to counteract excessive production of ROS and modulation of the anti-oxidant defence system in the endothelium elicits cellular damage and dysfunction [2].

Normal vascular endothelial physiology is dependent on NO production via coupling of the eNOS heme group with L-arginine using tetrahydrobiopterin $(\mathrm{BH} 4)$ as a cofactor [91]. Excess ROS induce the conversion of BH4 to 7,8-dihydrobiopterin (BH2) with subsequent eNOS uncoupling and synthesis of $\mathrm{O}_{2} \bullet$ instead of $\mathrm{NO}$ [91] (Figure 2). $\mathrm{O}_{2} \bullet$ can react with $\mathrm{NO}$ to produce the versatile oxidant peroxynitrite (ONOO-) [92]. The upregulation of iNOS and uncoupling of eNOS under hyperglycemic conditions are now well established [93, 94]. L-arginine is also a substrate for arginase [95] which is upregulated in the endothelium of coronary arterioles in hypertension and contributes to the impaired NO-mediated dilation [96].
In addition, ONOO- and hydrogen peroxide $\left(\mathrm{H}_{2} \mathrm{O}_{2}\right)$ were reported to increase the activity/expression of arginase in endothelial cells [97], thus exacerbating the defects in myogenic tone. Therefore, ROS can trigger eNOS uncoupling through depletion of the substrate L-arginine. This notion has been supported by the study of Romero et al. [98] where increased arginase activity elicited L-arginine depletion and contributed to endothelial dysfunction in diabetes. ONOO- can also activate NADPH oxidases and influences further generation of ROS [99]. Additionally, blockage of the mitochondrial electron transfer in complex III in diabetes leads to the release of electrons, which reduce molecular oxygen to $\mathrm{O}_{2} \bullet$ and increase intracellular ROS production [84]. Furthermore, ROS can activate membrane oxidases with a subsequent increase in the levels of asymmetric dimethylarginine that competes for the L-arginine transporters and active sites on eNOS [85].

Nrf2 in the endothelium can be activated via increased ROS production and PI3K-Akt signaling triggered by laminar shear stress [32]. In human arterial endothelial cells, Nrf2 activation resulted in increased intracellular HMOX1, GPx, GSH, GCLM, SRXN1, NQO1, PAR4, and OSGIN1 [27, 28, 100]. Adenoviral overexpression of $\mathrm{Nrf2}$ in endothelial cells infected showed decreased expression of TNF- $\alpha$, IL- $1 \beta$, MCP1, and VCAM1, pointing to the antiinflammatory potential of Nrf2 $[28,101]$. When shear stress is disturbed at bifurcations, curved sections of arteries or distal to regions of stenosis, NO bioavailability decreases, $\mathrm{O}_{2} \bullet$ generation increases [102], and Nrf2activated genes are diminished, causing the endothelium to become predisposed to atherogenesis [103]. Our recent studies have demonstrated that free fatty acid- (FFA-) induced excessive ROS production diminished both the gene and protein expression of Nrf2, NQO1, and HO-1 in endothelial cells [104]. In addition, upregulation of Nrf2/ARE/HMOX1 signaling protected the human endothelial cells against TNF- $\alpha$ activation [105]. It could be that mitochondrial ROS may trigger a protective response via Nrf2 activation in endothelial cells. The study of Lo and Hannink [106] suggested that Nrf2-KEAP1 complex binds to the mitochondria through interaction with mitochondrial outer membrane protein PGAM5 and directly senses mitochondrial ROS production.

Another possibility through which Nrf2 can protect the endothelium against the cytotoxic ROS involves regulating the catalytic subunit of GCLC which reduces GSH biosynthesis [107]. In this context, impaired Nrf2-KEAP1-GCLC has been demonstrated in high glucose-induced retinal endothelial cells from diabetic donors [108]. In the human brain microvascular endothelial cells (HBVEC), GSH conferred protection against FFA-induced oxidative stress and apoptosis by activating the Akt pathway [109]. Human umbilical vein endothelial cells (HUVECs), human coronary artery endothelial cells (HCAECs), and endothelial progenitor cells exposed to cytotoxic ROS showed apoptosis and cell death accompanied by diminished nuclear localization and transcriptional activity of Nrf2 [2]. These findings highlight the crucial role of Nrf2 activation in protecting endothelial cells against oxidative stress-induced dysfunction. 


\section{Nrf2 in Atherosclerosis}

Atherosclerosis is a focal inflammatory disease of the arterial system involving a number of different cell types. The focal nature of atherosclerosis highlights the involvement of local haemodynamics factors acting on the endothelium in the initiation and progression of atherosclerosis, which develops in regions that experience disturbed flow at bifurcations and curved sections of artery [110-113]. Straight sections of artery that experience normal laminar blood flow are relatively spared from disease through a coordinated modulation of gene expression, predominantly controlled by the transcription factors KLF2 and KLF4 and activation of Nrf2 $[29,32,114-116]$. By contrast, endothelial cells exposed to disturbed flow adopt a phenotype that amplifies endothelial dysfunction and increases permeability. While ROS are essential signaling molecules regulating vascular homeostasis, excessive ROS, elevated by many of the risk factors associated with the development of atherosclerosis, promote endothelial dysfunction and decrease NO availability. Thus, Nrf2-regulated antioxidant gene expression may play an atheroprotective role in endothelial cells.

Consistent with this hypothesis, the Nrf2-regulated gene, heme oxygenase 1 (HMOX1), demonstrates significant cytoprotective and anti-inflammatory effects that result in a reduction of atherosclerosis in mouse models [117], possibly through production of low levels of carbon monoxide. Hypercholesterolemic mice, deficient in both HMOX1 and ApoE $\left(\mathrm{HMOX1}^{-1-} / \mathrm{ApoE}^{---}\right)$, demonstrated enhanced development of atherosclerosis compared to $\mathrm{ApoE}^{-/-}$single knockout mice [118]. HMOX1 expression in macrophages plays a protective role in atherosclerosis [119] with macrophages from $\mathrm{HMOX1}^{-1-}$ mice displaying increased ROS generation, production of inflammatory cytokines, and increased foam cell formation when treated with oxLDL, attributable in part to increased expression of scavenger receptor A (SR-A). Smooth muscle cells from HMOX1 ${ }^{-/-}$ mice not only displayed increase neointimal formation but also enhanced cell death potentially due to greater susceptibility to oxidant stress [118]. Pharmacological modulation of HMOX1 expression also demonstrates a protective role of HMOX1 in atherogenesis $[120,121]$. In addition to the anti-inflammatory effects of carbon monoxide, hydrogen sulphide also elicits an anti-inflammatory antiatherogenic effect [122]. Hydrogen sulfide activates the release of Nrf2 from KEAP1, increasing Nrf2-dependent gene expression [122].

Despite the antioxidant function of Nrf2 and the antiatherogenic function of the key Nrf2 target gene HMOX1, the global knockout of $\mathrm{Nrf2}\left(\mathrm{Nrf2}^{-/-}\right)$developed less rather than more atherosclerosis $[123,124]$. Barajas et al. attributed this to an effect of Nrf2 in lipid metabolism, lowering plasma cholesterol and reducing foam cell formation [123], while Sussan et al. did not find a difference in serum cholesterol but attributed the effect to a reduction in scavenger receptor CD36 reducing foam cell formation [124]. The role of Nrf2 in NLRP3 inflammasome induction by cholesterol crystals within the atherosclerotic plaque may also be a contributing factor that explains the counterintuitive net detrimental effect of Nrf2 in hypercholesterolemic mouse models of atherosclerosis [125]. It might also explain why the expression of the Nrf2-regulated gene HMOX1 is highest in human plaques with the highest markers of plaque instability [121].

\section{Nrf2 in Vascular Calcification}

The presence of vascular calcification is often detected in atherosclerotic plaques and in patients with end-stage renal disease. Both of these pathologies have been targeted for prevention using pharmacological and genetic approaches by modulation of Nrf2 antioxidant pathways. For example, studies in vitro using rodent vascular smooth muscle cells show that dimethyfumarate or resveratrol could attenuate the deposition of a mineralised matrix and suggest protection against oxidative stress-induced mitochondrial damage, via activation of Nrf2 and SIRT1 signaling and downregulation of osteogenic transcription factors [126, 127]. In contrast, glucose-induced oxidative stress enhances the osteogenic differentiation and mineralisation of human embryonic stem (ES) cells, by the upregulation of runt-related transcription factor 2 (Runx2), Nrf2, and HMOX1, which was inhibited by Nrf2 knockdown [128] highlighting a context-specific regulation of the calcification process. Given the links between Nrf2 and bone homeostasis, it is not surprising to have an association between Nrf2 signaling and vascular calcification. Whether these initial in vitro studies can translate into the in vivo situation needs further study.

\section{Nrf2 in Hypertension}

Angiotensin II and associated renin-angiotensin system (RAS) are involved in the regulation of blood pressure, vasoconstriction, sodium intake, and potassium excretion [129]. Inappropriate activation of the RAS is the main cause of profound hypertension and cardiovascular morbidity. Angiotensin II increases the expression of NADPH oxidase and the generation of ROS potentially mediating some of the effects in renin-angiotensin-induced hypertension $[130,131]$. It has been suggested that hypertension could be one of the causes of Nrf2 misregulation and not vice versa [132] through enhanced oxidative stress and vascular dysfunction in a hypertensive rat model [133]. This would suggest that the Nrf2 anti-oxidant defence system is insufficient to counteract the effects of oxidative stress, possibly due to elevated levels of Nrf2 repressors in hypertensive animals. Research is now moving from the adaptive and protective changes in the Nrf2 antioxidant response to focusing on the alternative mechanisms intrinsic to upstream and downstream molecules associated with a defective Nrf2 signaling system. Enhancing Nrf2 activity may have a therapeutic potential for a meliorating hypertension.

\section{Nrf2 in Diabetic Cardiomyopathy}

The heart is particularly vulnerable to oxidative damage compared to other organs, due to its low basal levels of antioxidant defences [134]. Diabetic cardiomyopathy (DCM) and other cardiovascular complications account for more than $80 \%$ of deaths among patients with diabetes [135]. 


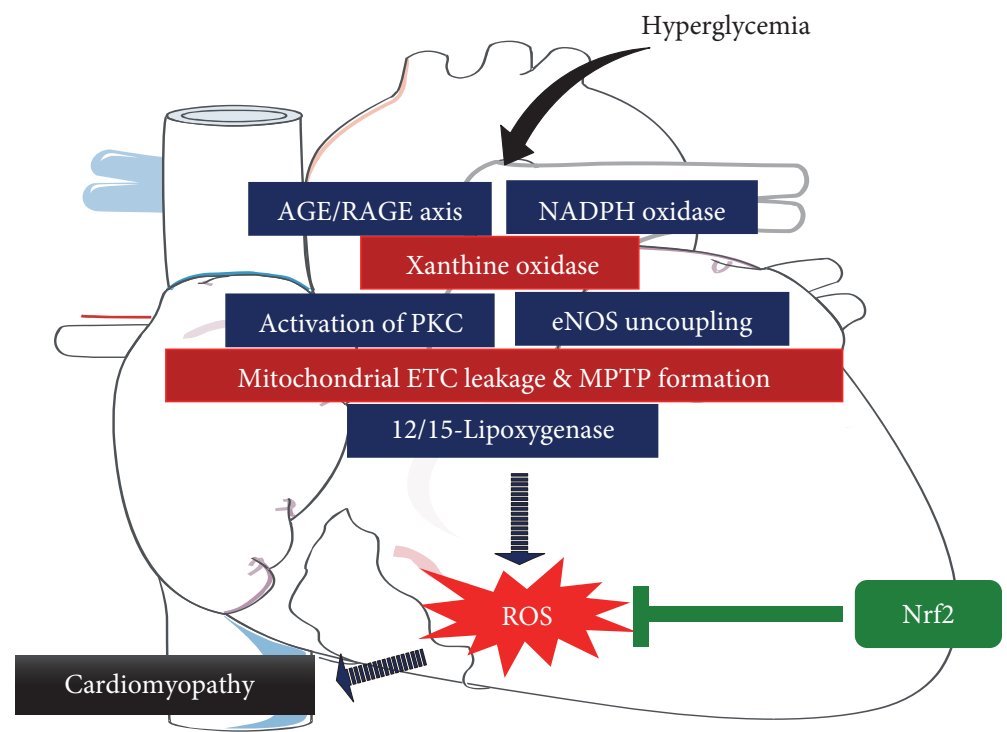

FIgURE 3: Hyperglycemia-induced ROS generation in the heart. A schematic model showing the potential pathways involved in cardiomyopathy and how Nrf2 could be targeted to reduce ROS and prevent the development of this pathology. AGEs: advanced glycation end products; NADPH: nicotinamide adenine dinucleotide phosphate; PKC: protein kinase C; eNOS: endothelial nitric oxide synthase; ETC: electron transport chain; MPTP: mitochondrial permeability transition pore.

DCM is characterized by impaired diastolic function, hypertrophy, apoptosis, and fibrosis of cardiomyocytes [136] and involves several mechanisms and pathogenic factors, with oxidative stress thought to be the common link [137-140]. Hyperglycemia generates excess ROS/RNS from activation of NADPH oxidases, PKC, leakage of the mitochondrial electron transport chain, eNOS uncoupling, AGE/RAGE signaling, xanthine oxidase, and 12/15-lipoxygenase (LOX) [141], impairing antioxidant defences in the diabetic heart [138, 140] (Figure 3).

Studies have established the importance of Nrf2/ARE signaling in the prevention of diabetic complications [142-144] and oxidative stress-induced cardiomyocyte injury $[145,146]$. Significantly reduced Nrf2 expression has been observed in the left ventricle of diabetic patient heart by histological analysis [147], which has also been observed in a diabetic mouse model after 5 months [147]. These findings suggest adaptive overexpression of Nrf2 to combat early oxidative damage in diabetes, which is overcome by sustained ROS production and exhaustion of the antioxidant defences [148]. This concept is supported by our findings in palmitatetreated endothelial cells, where reduced Nrf2 expression and antioxidant defences are observed with surplus ROS [104].

Furthermore, it has been demonstrated that Nrf2 and its downstream target genes are downregulated in cardiomyocytes from diabetic $(d b / d b)$ mice [146, 147], which may occur via extracellular signal-regulated protein kinase (ERK) $1 / 2$ activity [149, 150]. Isoproterenol-stimulated contraction of primary cardiomyocytes from adult diabetic mice was also shown to be dependent on Nrf2 [151]. Hence, hyperglycemia-induced loss of Nrf2 function exacerbates oxidative stress and leads to severe myocardial damage [151]. Nrf2 knockout mice exhibit structural and functional abnormalities under conditions of pathological stress [152], and cardiomyocytes from Nrf2-knockout mice showed significantly increased apoptosis following incubation with high glucose [151]. These findings highlight the importance of the Nrf2 protective mechanisms, and thus, novel therapeutics to enhance Nrf2 could be beneficial in this scenario. The proteasome inhibitor MG-132, which increases Nrf2 signaling, was reported to decrease left ventricle hypertrophy by reducing inflammation and lowering the risk of cardiomyopathy [153]. In addition, in a mouse model of type I diabetes mellitus, Nrf2 activation by sulforaphane reduced heart weight and decreased diabetesinduced atrial natriuretic peptide (ANP) expression, thought to be related to induction of DCM [154]. Therefore, enhancing endogenous Nrf 2 and subsequent antioxidant pathways in the heart is a potential strategy to prevent DCM $[138,155]$.

\section{Nrf2 in the Aging Heart}

Aging, a progressive decline of cellular functions, is related to the loss of homeostasis via a combination of epigenetic alterations and genetically programmed processes resulting in death $[156,157]$. Heart capacity declines with age, with a concomitant increased CVD risk [158]. Herman's free radical theory proposes that the accumulation of damaged biomolecules by ROS/RNS plays a central role in aging [159-161]. In turn, this leads to activation of NF- $\kappa \mathrm{B}$ [162], eliciting an inflammatory response via TNF- $\alpha$, IL- 6 , and $\mathrm{C}$ reactive protein (CRP), reported to be associated with aging [163], and further stimulation of ROS production through activation of NADPH oxidase $[164,165]$ and NF- $\kappa \mathrm{B}[166]$. In support of this, elderly patients demonstrate an impaired endothelial-dependent dilation, associated with excess ROS, activated NADPH oxidase, and increased NF- $\kappa \mathrm{B}$ [167].

Elevated ROS also increase the rate of apoptosis and necrosis in cardiomyocytes [168], resulting in functional and phenotypic changes, including decreased remodelling 
TABLE 2: The effect of Nrf2 activation on CVD.

\begin{tabular}{|c|c|c|c|}
\hline Activator & Animal model/cell line & Effects & Reference \\
\hline \multirow[t]{2}{*}{$\begin{array}{l}\text { Bardoxolone methyl } \\
\text { derivative dh404 }\end{array}$} & $\begin{array}{l}\text { Male Akita mice at } 26 \text { weeks of } \\
\text { age \& human aortic endothelial } \\
\text { cells (HAECs) }\end{array}$ & $\begin{array}{c}\text { Attenuation of endothelial dysfunction } \\
\text { Downregulation of inflammatory and } \\
\text { prooxidant genes } \\
\text { Reduction in systemic and vascular } \\
\text { oxidative stress }\end{array}$ & {$[188]$} \\
\hline & $\begin{array}{l}\text { Streptozotocin- }(\mathrm{STZ}-) \text { induced } \\
\text { diabetic } \mathrm{ApoE}^{-1-} \text { mice }\end{array}$ & Prevention of atherosclerosis & [189] \\
\hline \multirow{5}{*}{ Sulforaphane } & $\begin{array}{l}\text { Vascular smooth muscle cells } \\
\text { (VSMCs) }\end{array}$ & Suppression of VSMC proliferation & {$[190]$} \\
\hline & HUVECs & $\begin{array}{l}\text { Protection against oxidized low-density } \\
\text { lipoprotein- (oxLDL-) induced } \\
\text { endothelial damage }\end{array}$ & {$[191]$} \\
\hline & $\begin{array}{l}\text { High-fat diet- (HFD-) induced } \\
\text { type } 2 \text { diabetic mice }\end{array}$ & Prevention of aortic damage & {$[192]$} \\
\hline & Low-dose STZ diabetic mice & $\begin{array}{l}\text { Prevention of diabetic } \\
\text { cardiomyopathy }\end{array}$ & {$[154]$} \\
\hline & $\begin{array}{l}\text { Multiple low dose STZ-induced } \\
\text { type } 1 \text { diabetic mice }\end{array}$ & $\begin{array}{l}\text { Prevents aortic oxidative damage, } \\
\text { fibrosis, and inflammation }\end{array}$ & [193] \\
\hline Miltirone & EA.hy926 endothelial cells & $\begin{array}{c}\text { Protects against oxLDL-derived } \\
\text { oxidative stress } \\
\end{array}$ & {$[194]$} \\
\hline Epigallocatechin-3-gallate & HUVECs & $\begin{array}{c}\text { Protects against PM2.5-induced } \\
\text { oxidative stress }\end{array}$ & [195] \\
\hline $\begin{array}{l}\text { Barleria lupulina alkyl } \\
\text { catechols (4-ethylcatechol, } \\
\text { 4-vinylcatechol, and } \\
\text { 4-methylcatechol) }\end{array}$ & $\begin{array}{l}\text { Human dermal microvascular } \\
\text { endothelial cells }\end{array}$ & $\begin{array}{c}\text { Improves organization of the } \\
\text { cytoskeleton } \\
\text { Organizes tight cell junctions } \\
\text { Reduces inflammation and vascular leakage }\end{array}$ & {$[196]$} \\
\hline Small molecule glycomimetics & HUVECs & $\begin{array}{l}\text { Attenuates palmitate-induced oxidative stress } \\
\text { and endothelial dysfunction. } \\
\text { Increases NO production. }\end{array}$ & {$[104]$} \\
\hline Rutin & HUVECs & $\begin{array}{l}\text { Prevents hydrogen peroxide- }\left(\mathrm{H}_{2} \mathrm{O}_{2^{-}}\right) \\
\text {induced oxidative stress }\end{array}$ & [197] \\
\hline 1,25-Dihydroxycholecalciferol & HUVECs & $\begin{array}{l}\text { Prevents leptin-induced oxidative } \\
\text { stress and inflammation }\end{array}$ & [198] \\
\hline Willow bark extract & $\begin{array}{l}\text { HUVECs and Caenorhabditis } \\
\text { elegans }\end{array}$ & $\begin{array}{l}\text { Prevents ROS-induced cytotoxicity of } \\
\text { HUVECs and death of C. elegans }\end{array}$ & [199] \\
\hline Aged garlic extract & HUVECs & $\begin{array}{l}\text { Enhances HO-1 and glutamate-cysteine ligase } \\
\text { modifier subunit expression (GCLM) }\end{array}$ & [200] \\
\hline Celastrol & HUVECs & $\begin{array}{c}\text { Attenuates angiotensin II mediated } \\
\text { endothelial damage }\end{array}$ & {$[201]$} \\
\hline Paeotang & HUVECs & Prevents TNF- $\alpha$-induced vascular inflammation & {$[202]$} \\
\hline \multirow{3}{*}{ Cyanidin-3-O-glucoside } & HUVECs & $\begin{array}{l}\text { Ameliorates palmitate-induced insulin resistance } \\
\text { and endothelial derived vasoactive factors }\end{array}$ & [203] \\
\hline & & Attenuates palmitate-induced inflammation & {$[204]$} \\
\hline & EA.hy926 endothelial cells & $\begin{array}{l}\text { Attenuates angiotensin II-induced oxidative stress and } \\
\text { inflammation }\end{array}$ & [205] \\
\hline Piceatannol & HUVECs & $\begin{array}{l}\text { Attenuates homocysteine-induced endoplasmic } \\
\text { reticulum stress and cell damage }\end{array}$ & [206] \\
\hline \multirow[t]{2}{*}{ Equol } & ApoE ${ }^{-/-}$mice & $\begin{array}{l}\text { Attenuates atherosclerosis and inhibits } \\
\text { endoplasmic reticulum stress }\end{array}$ & \multirow[t]{2}{*}[207]{} \\
\hline & HUVECs & Abrogates apoptosis induced by t-BHP & \\
\hline Sheep/goat whey protein & EA.hy926 endothelial cells & Increases antioxidant defences & {$[208]$} \\
\hline Quercetin & HAECs & $\begin{array}{l}\text { Inhibits LPS-induced adhesion molecule } \\
\text { expression and ROS production }\end{array}$ & [209] \\
\hline
\end{tabular}


TABle 2: Continued.

\begin{tabular}{|c|c|c|c|}
\hline Activator & Animal model/cell line & Effects & Reference \\
\hline $\begin{array}{l}\text { Panax notoginseng } \\
\text { saponins and Ginsenoside } \\
\text { Rb1 }\end{array}$ & HUVECs & Suppresses monocyte adhesion and inhibits ROS & {$[210]$} \\
\hline Bortezomib & $\begin{array}{c}\text { Human microvascular } \\
\text { endothelial cells (HMECs) }\end{array}$ & Induces expression of $\mathrm{HO}-1$ & {$[211]$} \\
\hline Sofalcone & HUVECs & Suppresses endothelial dysfunction & {$[212]$} \\
\hline Salidroside & HUVECs & Suppresses ROS-induced damage & [213] \\
\hline Caffeic acid & HUVECs & $\begin{array}{l}\text { Attenuates high glucose-induced } \\
\text { endothelial dysfunction }\end{array}$ & {$[214]$} \\
\hline & H9c2 cardiomyocytes & Attenuates high glucose-induced apoptosis & {$[215]$} \\
\hline Myricitrin & $\begin{array}{l}\text { STZ-induced diabetic mice \& } \\
\text { AGE-induced H9c2 } \\
\text { cardiomyocytes }\end{array}$ & $\begin{array}{l}\text { Alleviates oxidative stress-induced } \\
\text { inflammation, apoptosis, and cardiomyopathy }\end{array}$ & [216] \\
\hline Andrographolide & EA.hy926 endothelial cells & $\begin{array}{l}\text { Inhibits hypoxia-induced HIF-1 } \alpha \text {-driven } \\
\text { endothelin } 1 \text { secretion }\end{array}$ & [217] \\
\hline Tanshinone IIA & HUVECs & $\begin{array}{c}\text { Inhibits cyclic strain-induced expression } \\
\text { of interleukin } 8\end{array}$ & [218] \\
\hline Lycopene & HUVECs & $\begin{array}{c}\text { Inhibits cyclic strain-induced endothelin-1 } \\
\text { expression } \\
\text { and oxidative stress }\end{array}$ & [219] \\
\hline Withaferin A & $\begin{array}{l}\text { EA.hy926 endothelial cells \& } \\
\text { HUVECs }\end{array}$ & Induces HO-1 expression & {$[220]$} \\
\hline $\begin{array}{l}\text { Copper } \\
\text { diethyldithiocarbamate }\end{array}$ & Bovine aortic endothelial cells & $\begin{array}{l}\text { Inhibits proteasome and Nrf2 binding to } \\
\text { Kelch-like ECH-associated protein } 1\end{array}$ & [221] \\
\hline Clopidogrel & HAECs & Hinders TNF- $\alpha$-induced VCAM- 1 expression & [222] \\
\hline Hericium erinaceus & EA.hy926 endothelial cells & $\begin{array}{l}\text { Inhibits TNF- } \alpha \text {-induced angiogenesis } \\
\text { and ROS generation }\end{array}$ & [223] \\
\hline Andrographolide & Primary cerebral endothelial cells & $\begin{array}{c}\text { Prevents middle cerebral artery } \\
\text { occlusion- (MCAO-) induced ischemic stroke }\end{array}$ & {$[224]$} \\
\hline Butin & C57/BL6J diabetic mice & $\begin{array}{l}\text { Prevents ischemia/reperfusion-induced } \\
\text { myocardial injury }\end{array}$ & [225] \\
\hline Aspalathin & $\begin{array}{l}\text { H9c2 cardiomyocytes and } \\
\text { diabetic } \mathrm{db} / \mathrm{db} \text { mice }\end{array}$ & $\begin{array}{c}\text { Protects against hyperglycemia-induced } \\
\text { oxidative damage and apoptosis }\end{array}$ & {$[146]$} \\
\hline Broccoli sprout & Diabetic $\mathrm{db} / \mathrm{db}$ mice & Prevents diabetic cardiomyopathy & {$[226]$} \\
\hline Oleuropein & Spontaneously hypertensive rats & $\begin{array}{l}\text { Attenuates oxidative stress and improves } \\
\text { mitochondrial function in the hypothalamic } \\
\text { paraventricular nucleus }\end{array}$ & {$[227]$} \\
\hline Aralia taibaiensis & H9c2 cardiomyocytes & $\begin{array}{l}\text { Protects against high glucose-induced } \\
\text { oxidative stress and apoptosis }\end{array}$ & [228] \\
\hline Compound C66 & STZ-induced diabetic mice aorta & $\begin{array}{c}\text { Prevents oxidative and nitrative stress, } \\
\text { inflammation, apoptosis, cell } \\
\text { proliferation, and fibrosis }\end{array}$ & [229] \\
\hline Dimethyl fumarate & VSMCs & Attenuates vascular calcification & [127] \\
\hline Gemigliptin & VSMCs & Prevents proliferation and migration of VSMCs & {$[230]$} \\
\hline L6H9 (chalcone) & H9c2 cardiomyocytes & $\begin{array}{l}\text { Prevents hyperglycemia-induced oxidative } \\
\text { stress and inflammation }\end{array}$ & {$[231]$} \\
\hline $\begin{array}{l}\text { Magnesium } \\
\text { lithospermate B }\end{array}$ & VSMCs & Prevents proliferation and migration of VSMCs & [232] \\
\hline 4-O-methylhonokiol & HFD-induced obese mice & Prevents cardiac pathogenesis & [233] \\
\hline
\end{tabular}


TABLe 2: Continued.

\begin{tabular}{|c|c|c|c|}
\hline Activator & Animal model/cell line & Effects & Reference \\
\hline \multirow{4}{*}{ Resveratrol } & Coronary arterial endothelial cells & $\begin{array}{l}\text { Protects against high glucose-induced } \\
\text { endothelial protection }\end{array}$ & [234] \\
\hline & VSMCs & Ameliorates vascular calcification & {$[126]$} \\
\hline & $\mathrm{db} / \mathrm{db}$ mice & Ameliorates vascular inflammation & [235] \\
\hline & STZ-induced type 2 diabetic rats & Ameliorates vascular inflammation & {$[236]$} \\
\hline \multirow[t]{2}{*}{ MG132 } & \multirow[t]{2}{*}{ OVE26 type 1 diabetic mice } & $\begin{array}{l}\text { Prevents aortic oxidative damage and } \\
\text { inflammatory response }\end{array}$ & {$[237]$} \\
\hline & & Prevents cardiomyopathy & {$[238]$} \\
\hline
\end{tabular}

[169], cardiac hypertrophy [170], and increased systolic pressure $[171,172]$. NADPH oxidase-2, its activator RAC1, and several profibrotic factors are elevated in hypertrophic hearts in aged rats [158], pointing to the important role of NADPH oxidase in aging-associated cardiomyocyte remodelling. Ischemia and reperfusion are characterized by increased accumulation of intracellular $\mathrm{Ca}^{2+}$, altered substrate utilization, and elevated ROS production in the heart [173], which can damage ionic pumps and induce mitochondrial dysfunction via lipid peroxidation [174]. This damage can lead to necrotic cell death [175] and is exacerbated with aging $[160,176]$, as shown in mitochondria from aged rats [177].

Diminished activity of Nrf2 resulting in oxidative stress, apoptosis, and/or necrosis in the myocardium has been reported [178-180], thus predisposing the heart to disease [180]. Studies in mouse models have supported the notion that Nrf2 is involved in counteracting aging-associated cardiac effects via ARE signaling and expression of antioxidant enzymes. Bailey-Downs et al. [181] reported increased sensitivity of blood vessels to stress-induced damage along with impaired activity of $\mathrm{Nrf} 2$ in insulinlike growth factor 1 (Igf1) knockout mice, promoting an aging phenotype. Nrf2-knockout mice showed exaggerated cardiac hypertrophy, heart failure, increased mortality [152], and oxidative stress [182]. Aged rhesus macaques have shown increased ROS and decreased nuclear translocation of Nrf2 and protein expression of NQO1 and HO-1 in their carotid arteries [183]. Vascular smooth muscle cells (VSMCs) derived from old monkeys have exhibited diminished Nrf2 activation following incubation with high glucose as compared with those derived from younger monkeys [183]. Additionally, El Assar et al. [165] have reported a decreased expression of Nrf2-regulated antioxidants in aged vessels.

These data demonstrate clearly that decreasing levels of Nrf2 are age-dependent but may be reversed by exercising. Muthusamy et al. [184] demonstrated an increased nuclear translocation of Nrf2 in the hearts of mice following acute exercise training. They attributed their findings to the induction of an exercise-induced mild oxidative state. Endurance exercise training was reported to promote Nrf2 signaling and enhance antioxidant capacity in the hearts of 6-month-old mice [185], which might offset the reduced signaling observed in aged mice and men [171, 185-187].

\section{Role of Nrf2 Activation in the Treatment of CVD}

The role of activators of Nrf2 in attenuating oxidative stressmediated cardiovascular disorders has been identified. In Table 2, we present a summary of the recently studied activators of Nrf2 and their beneficial effects in CVD.

\section{Conclusions}

The Nrf2 antioxidant system plays a significant role in cellular defence against free radical damage, while insufficiency of Nrf2-dependent gene expression is clearly implicated in multiple aspects and stages of CVD. Enhancing Nrf2 activity may be beneficial in diabetic cardiomyopathy, mitochondrial dysfunction, and reducing the effects of aging in the heart; however, the potential exacerbation of atherosclerosis by Nrf2-mediated inflammasome activation in plaque macrophages, along with the lethality of KEAP1 knockout mice, raises a cautionary note to pharmacological activation of $\mathrm{Nrf} 2$ as a therapeutic strategy. Selective upregulation of Nrf2 target genes such as HMOX1 may provide a more amenable therapeutic strategy. Modest activation of Nrf2 by dietary factors, such as sulforaphane, found in brassicas like broccoli, may highlight mild activation of Nrf2 as part of the protective role played in eating a healthy balanced diet, which may be sufficient to maximise the therapeutic benefit offered through the control of this gene expression network.

\section{Conflicts of Interest}

The authors have no conflicts of interest to declare.

\section{Authors' Contributions}

Sandro Satta and Ayman M. Mahmoud contributed equally to this work.

\section{References}

[1] D. Tousoulis, N. Papageorgiou, E. Androulakis et al., "Diabetes mellitus-associated vascular impairment: novel circulating biomarkers and therapeutic approaches," Journal of the American College of Cardiology, vol. 62, no. 8, pp. 667-676, 2013. 
[2] B. Chen, Y. Lu, Y. Chen, and J. Cheng, "The role of Nrf2 in oxidative stress-induced endothelial injuries," The Journal of Endocrinology, vol. 225, no. 3, pp. R83-R99, 2015.

[3] T. Finkel and N. J. Holbrook, "Oxidants, oxidative stress and the biology of ageing," Nature, vol. 408, no. 6809, pp. 239-247, 2000.

[4] Y. Zhang, A. Unnikrishnan, S. S. Deepa et al., "A new role for oxidative stress in aging: the accelerated aging phenotype in Sod $1^{-1-}$ mice is correlated to increased cellular senescence," Redox Biology, vol. 11, pp. 30-37, 2017.

[5] H. Cui, Y. Kong, and H. Zhang, "Oxidative stress, mitochondrial dysfunction, and aging," Journal of Signal Transduction, vol. 2012, Article ID 646354, 13 pages, 2012.

[6] E. Birben, U. M. Sahiner, C. Sackesen, S. Erzurum, and O. Kalayci, "Oxidative stress and antioxidant defense," The World Allergy Organization journal, vol. 5, no. 1, pp. 9-19, 2012.

[7] P. Moi, K. Chan, I. Asunis, A. Cao, and Y. W. Kan, "Isolation of NF-E2-related factor 2 (Nrf2), a NF-E2-like basic leucine zipper transcriptional activator that binds to the tandem NF-E2/AP1 repeat of the beta-globin locus control region," Proceedings of the National Academy of Sciences, vol. 91, no. 21, pp. 9926-9930, 1994.

[8] R. Venugopal and A. K. Jaiswal, "Nrf1 and Nrf2 positively and c-Fos and Fral negatively regulate the human antioxidant response element-mediated expression of $\mathrm{NAD}(\mathrm{P}) \mathrm{H}:-$ quinone oxidoreductase1 gene," Proceedings of the National Academy of Sciences, vol. 93, no. 25, pp. 14960-14965, 1996.

[9] R. Venugopal and A. K. Jaiswal, "Nrf2 and Nrf1 in association with Jun proteins regulate antioxidant response elementmediated expression and coordinated induction of genes encoding detoxifying enzymes," Oncogene, vol. 17, no. 24, pp. 3145-3156, 1998.

[10] M. Zhang, C. An, Y. Gao, R. K. Leak, J. Chen, and F. Zhang, "Emerging roles of Nrf2 and phase II antioxidant enzymes in neuroprotection," Progress in Neurobiology, vol. 100, pp. 30-47, 2013.

[11] N. Wakabayashi, K. Itoh, J. Wakabayashi et al., "Keap1-null mutation leads to postnatal lethality due to constitutive Nrf2 activation," Nature Genetics, vol. 35, no. 3, pp. 238245, 2003.

[12] H. K. Bryan, A. Olayanju, C. E. Goldring, and B. K. Park, "The Nrf2 cell defence pathway: Keap1-dependent and -independent mechanisms of regulation," Biochemical Pharmacology, vol. 85, no. 6, pp. 705-717, 2013.

[13] D. Cheng, R. Wu, Y. Guo, and A.-N. T. Kong, "Regulation of Keap1-Nrf2 signaling: the role of epigenetics," Current Opinion in Toxicology, vol. 1, pp. 134-138, 2016.

[14] M. Kobayashi and M. Yamamoto, "Molecular mechanisms activating the Nrf2-Keap1 pathway of antioxidant gene regulation," Antioxidants \& Redox Signaling, vol. 7, no. 3-4, pp. 385-394, 2005.

[15] K. Itoh, N. Wakabayashi, Y. Katoh et al., "Keap1 represses nuclear activation of antioxidant responsive elements by Nrf2 through binding to the amino-terminal Neh2 domain," Genes \& Development, vol. 13, no. 1, pp. 76-86, 1999.

[16] A. T. Dinkova-Kostova, W. D. Holtzclaw, R. N. Cole et al., "Direct evidence that sulfhydryl groups of Keap1 are the sensors regulating induction of phase 2 enzymes that protect against carcinogens and oxidants," Proceedings of the
National Academy of Sciences, vol. 99, no. 18, pp. 1190811913, 2002.

[17] G. Rachakonda, Y. Xiong, K. R. Sekhar, S. L. Stamer, D. C. Liebler, and M. L. Freeman, "Covalent modification at Cys151 dissociates the electrophile sensor Keap1 from the ubiquitin ligase CUL3," Chemical Research in Toxicology, vol. 21, no. 3, pp. 705-710, 2008.

[18] A. L. Eggler, G. Liu, J. M. Pezzuto, R. B. van Breemen, and A. D. Mesecar, "Modifying specific cysteines of the electrophile-sensing human Keap1 protein is insufficient to disrupt binding to the Nrf2 domain Neh2," Proceedings of the National Academy of Sciences of the United States of America, vol. 102, no. 29, pp. 10070-10075, 2005.

[19] N. D. Camp, R. G. James, D. W. Dawson et al., "Wilms tumor gene on X chromosome (WTX) inhibits degradation of NRF2 protein through competitive binding to KEAP1 protein," Journal of Biological Chemistry, vol. 287, no. 9, pp. 65396550, 2012.

[20] B. E. Hast, D. Goldfarb, K. M. Mulvaney et al., "Proteomic analysis of ubiquitin ligase KEAP1 reveals associated proteins that inhibit NRF2 ubiquitination," Cancer Research, vol. 73, no. 7, pp. 2199-2210, 2013.

[21] W. Chen, Z. Sun, X.-J. Wang et al., "Direct interaction between Nrf2 and p21Cip1/WAF1 upregulates the Nrf2mediated antioxidant response," Molecular Cell, vol. 34, no. 6, pp. 663-673, 2009.

[22] W. W. Wasserman and W. E. Fahl, "Functional antioxidant responsive elements," Proceedings of the National Academy of Sciences of the United States of America, vol. 94, no. 10, pp. 5361-5366, 1997.

[23] H. Zhang and H. J. Forman, "Reexamination of the electrophile response element sequences and context reveals a lack of consensus in gene function," Biochimica et Biophysica Acta (BBA)-Gene Regulatory Mechanisms, vol. 1799, no. 7, pp. 496-501, 2010.

[24] H.-K. Jyrkkanen, E. Kansanen, M. Inkala et al., "Nrf2 regulates antioxidant gene expression evoked by oxidized phospholipids in endothelial cells and murine arteries in vivo," Circulation Research, vol. 103, no. 1, pp. e1-e9, 2008.

[25] M. McMahon, D. J. Lamont, K. A. Beattie, and J. D. Hayes, "Keap1 perceives stress via three sensors for the endogenous signaling molecules nitric oxide, zinc, and alkenals," Proceedings of the National Academy of Sciences, vol. 107, no. 44, pp. 18838-18843, 2010.

[26] T. Rangasamy, C. Y. Cho, R. K. Thimmulappa et al., "Genetic ablation of Nrf2 enhances susceptibility to cigarette smokeinduced emphysema in mice," Journal of Clinical Investigation, vol. 114, no. 9, pp. 1248-1259, 2004.

[27] J. E. Teasdale, A. C. Newby, N. J. Timpson, M. R. Munafo, and S. J. White, "Cigarette smoke but not electronic cigarette aerosol activates a stress response in human coronary artery endothelial cells in culture," Drug and Alcohol Dependence, vol. 163, pp. 256-260, 2016.

[28] J. E. Teasdale, G. G. J. Hazell, A. M. G. Peachey et al., "Cigarette smoke extract profoundly suppresses $\mathrm{TNF} \alpha$-mediated proinflammatory gene expression through upregulation of ATF3 in human coronary artery endothelial cells," Scientific Reports, vol. 7, article 39945, 2017.

[29] S. R. McSweeney, E. Warabi, and R. C. M. Siow, "Nrf2 as an endothelial mechanosensitive transcription factor: going with the flow," Hypertension, vol. 67, no. 1, pp. 20-29, 2016. 
[30] T. Hosoya, A. Maruyama, M. I. Kang et al., "Differential responses of the Nrf2-Keap1 system to laminar and oscillatory shear stresses in endothelial cells," Journal of Biological Chemistry, vol. 280, no. 29, pp. 27244-27250, 2005.

[31] E. Warabi, W. Takabe, T. Minami et al., "Shear stress stabilizes NF-E2-related factor 2 and induces antioxidant genes in endothelial cells: role of reactive oxygen/nitrogen species," Free Radical Biology and Medicine, vol. 42, no. 2, pp. 260269, 2007.

[32] X. Chen, S. Varner, A. Rao et al., "Laminar flow induction of antioxidant response element-mediated genes in endothelial cells - a novel anti-inflammatory mechanism," The Journal of Biological Chemistry, vol. 278, pp. 703-711, 2003.

[33] G. Dai, S. Vaughn, Y. Zhang, E. T. Wang, G. GarciaCardena, and M. A. Gimbrone, "Biomechanical forces in atherosclerosis-resistant vascular regions regulate endothelial redox balance via phosphoinositol 3-kinase/Akt-dependent activation of Nrf2," Circulation Research, vol. 101, no. 7, pp. 723-733, 2007.

[34] J. O. Fledderus, R. A. Boon, O. L. Volger et al., "KLF2 primes the antioxidant transcription factor Nrf2 for activation in endothelial cells," Arteriosclerosis, Thrombosis, and Vascular Biology, vol. 28, no. 7, pp. 1339-1346, 2008.

[35] S. A. Rushworth, S. Shah, and D. J. MacEwan, "TNF mediates the sustained activation of Nrf2 in human monocytes," The Journal of Immunology, vol. 187, no. 2, pp. 702-707, 2011.

[36] C. A. Houghton, R. G. Fassett, and J. S. Coombes, "Sulforaphane and other nutrigenomic Nrf2 activators: can the clinician's expectation be matched by the reality?," Oxidative Medicine and Cellular Longevity, vol. 2016, Article ID 7857186, 17 pages, 2016.

[37] Y.-S. Keum, S. Yu, P. P.-J. Chang et al., "Mechanism of action of sulforaphane: inhibition of $\mathrm{p} 38$ mitogen-activated protein kinase isoforms contributing to the induction of antioxidant response element-mediated heme oxygenase- 1 in human hepatoma HepG2 cells," Cancer Research, vol. 66, no. 17, pp. 8804-8813, 2006.

[38] D.-S. Lee, K.-S. Kim, W. Ko et al., "The cytoprotective effect of sulfuretin against tert-butyl hydroperoxideinduced hepatotoxicity through Nrf2/ARE and JNK/ERK MAPK-mediated heme oxygenase-1 expression," International Journal of Molecular Sciences, vol. 15, no. 5, pp. 8863-8877, 2014.

[39] V. Kumar, S. Kumar, M. Hassan et al., "Novel chalcone derivatives as potent Nrf2 activators in mice and human lung epithelial cells," Journal of Medicinal Chemistry, vol. 54, no. 12, pp. 4147-4159, 2011

[40] M. Cuendet, C. P. Oteham, R. C. Moon, and J. M. Pezzuto, "Quinone reductase induction as a biomarker for cancer chemoprevention," Journal of Natural Products, vol. 69, no. 3, pp. 460-463, 2006.

[41] P. Rada, A. I. Rojo, S. Chowdhry, M. McMahon, J. D. Hayes, and A. Cuadrado, "SCF/ $\beta$-TrCP promotes glycogen synthase kinase 3-dependent degradation of the Nrf2 transcription factor in a Keap1-independent manner," Molecular and Cellular Biology, vol. 31, no. 6, pp. 1121-1133, 2011.

[42] M. McMahon, K. Itoh, M. Yamamoto, and J. D. Hayes, "Keap1-dependent proteasomal degradation of transcription factor Nrf2 contributes to the negative regulation of antioxidant response element-driven gene expression," Journal of Biological Chemistry, vol. 278, no. 24, pp. 21592-21600, 2003.
[43] A. Mitra, A. Ray, R. Datta, S. Sengupta, and S. Sarkar, "Cardioprotective role of P38 MAPK during myocardial infarction via parallel activation of $\alpha$-crystallin B and Nrf2," Journal of Cellular Physiology, vol. 229, no. 9, pp. 1272-1282, 2014.

[44] A. Kobayashi, M.-I. Kang, H. Okawa et al., "Oxidative stress sensor Keap1 functions as an adaptor for Cul3-based E3 ligase to regulate proteasomal degradation of Nrf2," Molecular and Cellular Biology, vol. 24, no. 16, pp. 7130-7139, 2004.

[45] S. K. Niture and A. K. Jaiswal, "Prothymosin- $\alpha$ mediates nuclear import of the INrf2/Cul3.Rbx1 complex to degrade nuclear Nrf2," Journal of Biological Chemistry, vol. 284, no. 20, pp. 13856-13868, 2009.

[46] K. Igarashi, H. Hoshino, A. Muto et al., "Multivalent DNA binding complex generated by small Maf and Bach1 as a possible biochemical basis for $\beta$-globin locus control region complex," Journal of Biological Chemistry, vol. 273, no. 19, pp. 11783-11790, 1998.

[47] H. Hoshino, A. Kobayashi, M. Yoshida et al., "Oxidative stress abolishes leptomycin B-sensitive nuclear export of transcription repressor Bach2 that counteracts activation of Maf recognition element," Journal of Biological Chemistry, vol. 275, no. 20, pp. 15370-15376, 2000.

[48] S. Dhakshinamoorthy, A. K. Jain, D. A. Bloom, and A. K. Jaiswal, "Bach1 competes with Nrf2 leading to negative regulation of the antioxidant response element (ARE)-mediated $\mathrm{NAD}(\mathrm{P}) \mathrm{H}$ :quinone oxidoreductase 1 gene expression and induction in response to antioxidants," Journal of Biological Chemistry, vol. 280, no. 17, pp. 16891-16900, 2005.

[49] H. Suzuki, S. Tashiro, J. Sun, H. Doi, S. Satomi, and K. Igarashi, "Cadmium induces nuclear export of Bach1, a transcriptional repressor of heme oxygenase-1 gene," Journal of Biological Chemistry, vol. 278, no. 49, pp. 49246-49253, 2003.

[50] J. W. Kaspar and A. K. Jaiswal, "Antioxidant-induced phosphorylation of tyrosine 486 leads to rapid nuclear export of Bach1 that allows Nrf2 to bind to the antioxidant response element and activate defensive gene expression," Journal of Biological Chemistry, vol. 285, no. 1, pp. 153-162, 2010.

[51] A. K. Jain and A. K. Jaiswal, "Phosphorylation of tyrosine 568 controls nuclear export of Nrf2," Journal of Biological Chemistry, vol. 281, no. 17, pp. 12132-12142, 2006.

[52] A. K. Jain and A. K. Jaiswal, "GSK- $3 \beta$ acts upstream of Fyn kinase in regulation of nuclear export and degradation of NF-E2 related factor 2," Journal of Biological Chemistry, vol. 282, no. 22, pp. 16502-16510, 2007.

[53] S. K. Niture, A. K. Jain, P. M. Shelton, and A. K. Jaiswal, "Src subfamily kinases regulate nuclear export and degradation of transcription factor Nrf2 to switch off Nrf2-mediated antioxidant activation of cytoprotective gene expression," Journal of Biological Chemistry, vol. 286, no. 33, pp. 28821-28832, 2011.

[54] K. Itoh, T. Chiba, S. Takahashi et al., "An Nrf2/small Maf heterodimer mediates the induction of phase II detoxifying enzyme genes through antioxidant response elements," Biochemical and Biophysical Research Communications, vol. 236, no. 2, pp. 313-322, 1997.

[55] K. I. Tong, Y. Katoh, H. Kusunoki, K. Itoh, T. Tanaka, and M. Yamamoto, "Keap1 recruits Neh2 through binding to ETGE and DLG motifs: characterization of the two-site molecular recognition model," Molecular and Cellular Biology, vol. 26, no. 8, pp. 2887-2900, 2006.

[56] P. Nioi, T. Nguyen, P. J. Sherratt, and C. B. Pickett, "The carboxy-terminal Neh3 domain of Nrf2 is required for 
transcriptional activation," Molecular and Cellular Biology, vol. 25, no. 24, pp. 10895-10906, 2005.

[57] J.-H. Kim, S. Yu, J. D. Chen, and A. N. T. Kong, "The nuclear cofactor RAC3/AIB1/SRC-3 enhances Nrf2 signaling by interacting with transactivation domains," Oncogene, vol. 32, no. 4, pp. 514-527, 2013.

[58] Y. Katoh, K. Itoh, E. Yoshida, M. Miyagishi, A. Fukamizu, and M. Yamamoto, "Two domains of Nrf2 cooperatively bind CBP, a CREB binding protein, and synergistically activate transcription," Genes to Cells, vol. 6, no. 10, pp. 857-868, 2001.

[59] Z. Sun, Y. E. Chin, and D. D. Zhang, "Acetylation of Nrf2 by p300/CBP augments promoter-specific DNA binding of Nrf2 during the antioxidant response," Molecular and Cellular Biology, vol. 29, no. 10, pp. 2658-2672, 2009.

[60] W. Li, S.-W. Yu, and A.-N. T. Kong, "Nrf2 possesses a redoxsensitive nuclear exporting signal in the Neh5 transactivation domain," Journal of Biological Chemistry, vol. 281, no. 37, pp. 27251-27263, 2006.

[61] H. Wang, K. Liu, M. Geng et al., "RXR $\alpha$ inhibits the NRF2ARE signaling pathway through a direct interaction with the Neh7 domain of NRF2," Cancer Research, vol. 73, no. 10, pp. 3097-3108, 2013.

[62] K. Itoh, J. Mimura, and M. Yamamoto, "Discovery of the negative regulator of Nrf2, Keap1: a historical overview," Antioxidants \& Redox Signaling, vol. 13, no. 11, pp. 16651678, 2010.

[63] L. M. Zipper and R. T. Mulcahy, "The Keap1 BTB/POZ dimerization function is required to sequester Nrf2 in cytoplasm," Journal of Biological Chemistry, vol. 277, no. 39, pp. 36544-36552, 2002.

[64] T. Yamamoto, T. Suzuki, A. Kobayashi et al., "Physiological significance of reactive cysteine residues of Keap1 in determining Nrf2 activity," Molecular and Cellular Biology, vol. 28, no. 8, pp. 2758-2770, 2008.

[65] N. Wakabayashi, A. T. Dinkova-Kostova, W. D. Holtzclaw et al., "Protection against electrophile and oxidant stress by induction of the phase 2 response: fate of cysteines of the Keap1 sensor modified by inducers," Proceedings of the National Academy of Sciences, vol. 101, no. 7, pp. 20402045, 2004.

[66] W. D. Kim, Y. W. Kim, I. J. Cho, C. H. Lee, and S. G. Kim, "E-cadherin inhibits nuclear accumulation of Nrf2: implications for chemoresistance of cancer cells," Journal of Cell Science, vol. 125, no. 5, pp. 1284-1295, 2012.

[67] H. J. Kang, Y. B. Hong, H. J. Kim, and I. Bae, "CR6interacting factor 1 (CRIF1) regulates NF-E2-related factor 2 (NRF2) protein stability by proteasome-mediated degradation," Journal of Biological Chemistry, vol. 285, no. 28, pp. 21258-21268, 2010.

[68] C. H. He, P. Gong, B. Hu et al., "Identification of activating transcription factor 4 (ATF4) as an Nrf2-interacting protein: implication for heme oxygenase-1 gene regulation," Journal of Biological Chemistry, vol. 276, no. 24, pp. 20858-20865, 2001.

[69] J. Zhang, T. Ohta, A. Maruyama et al., "BRG1 interacts with Nrf2 to selectively mediate HO-1 induction in response to oxidative stress," Molecular and Cellular Biology, vol. 26, no. 21, pp. 7942-7952, 2006.

[70] M. G. Marini, I. Asunis, K. Chan et al., "Cloning MafF by recognition site screening with the NFE2 tandem repeat of HS2: analysis of its role in globin and GCSl genes regulation,"
Blood Cells, Molecules, and Diseases, vol. 29, no. 2, pp. 145158, 2002.

[71] T. Toki, J. Itoh, J. Kitazawa et al., "Human small Maf proteins form heterodimers with $\mathrm{CNC}$ family transcription factors and recognize the NF-E2 motif," Oncogene, vol. 14, no. 16, pp. 1901-1910, 1997.

[72] Y. Wang, W. Devereux, T. M. Stewart, and R. A. Casero, "Characterization of the interaction between the transcription factors human polyamine modulated factor (PMF-1) and NF-E2-related factor 2 (Nrf-2) in the transcriptional regulation of the spermidine/spermine $\mathrm{N} 1$-acetyltransferase (SSAT) gene," Biochemical Journal, vol. 355, no. 1, pp. 4549, 2001

[73] H.-C. Huang, T. Nguyen, and C. B. Pickett, "Phosphorylation of Nrf2 at Ser- 40 by protein kinase $\mathrm{C}$ regulates antioxidant response element-mediated transcription," Journal of Biological Chemistry, vol. 277, no. 45, pp. 42769-42774, 2002.

[74] D. A. Bloom and A. K. Jaiswal, "Phosphorylation of Nrf2 at Ser40 by protein kinase $\mathrm{C}$ in response to antioxidants leads to the release of Nrf2 from INrf2, but is not required for Nrf2 stabilization/accumulation in the nucleus and transcriptional activation of antioxidant response element-mediated NAD(P)H:quinone oxidoreductase-1 gene expression," Journal of Biological Chemistry, vol. 278, no. 45, pp. 44675-44682, 2003.

[75] D.-Y. Lee, C.-I. Lee, T.-E. Lin et al., "Role of histone deacetylases in transcription factor regulation and cell cycle modulation in endothelial cells in response to disturbed flow," Proceedings of the National Academy of Sciences, vol. 109, no. 6, pp. 1967-1972, 2012.

[76] S. Levy and H. J. Forman, "C-Myc is a Nrf2-interacting protein that negatively regulates phase II genes through their electrophile responsive elements," IUBMB Life, vol. 62, no. 3, pp. 237-246, 2010.

[77] Y. Ikeda, A. Sugawara, Y. Taniyama et al., "Suppression of rat thromboxane synthase gene transcription by peroxisome proliferator-activated receptor $\gamma$ in macrophages via an interaction with NRF2," Journal of Biological Chemistry, vol. 275, no. 42 , pp. $33142-33150,2000$.

[78] W. H. Organisation, Cardiovascular diseases (CVDs), 2017, http://www.who.int/mediacentre/factsheets/fs317/en/.

[79] K. Cervantes Gracia, D. Llanas-Cornejo, and H. Husi, "CVD and oxidative stress," Journal of Clinical Medicine, vol. 6, no. 2, p. 22, 2017.

[80] A. Faria and S. J. Persaud, "Cardiac oxidative stress in diabetes: mechanisms and therapeutic potential," Pharmacology \& Therapeutics, vol. 172, pp. 50-62, 2017.

[81] M. Kim, C.-h. Han, and M.-Y. Lee, "NADPH oxidase and the cardiovascular toxicity associated with smoking," Toxicological Research, vol. 30, no. 3, pp. 149-157, 2014.

[82] Y. Taniyama and K. K. Griendling, "Reactive oxygen species in the vasculature," Molecular and Cellular Mechanisms, vol. 42, no. 6, pp. 1075-1081, 2003.

[83] N. Marui, M. K. Offermann, R. Swerlick et al., "Vascular cell adhesion molecule-1 (VCAM-1) gene transcription and expression are regulated through an antioxidantsensitive mechanism in human vascular endothelial cells," The Journal of Clinical Investigation, vol. 92, no. 4, pp. 1866-1874, 1993.

[84] P. Newsholme, E. P. Haber, S. M. Hirabara et al., "Diabetes associated cell stress and dysfunction: role of mitochondrial 
and non-mitochondrial ROS production and activity," The Journal of Physiology, vol. 583, Part 1, pp. 9-24, 2007.

[85] S. J. Chien, K. M. Lin, H. C. Kuo et al., "Two different approaches to restore renal nitric oxide and prevent hypertension in young spontaneously hypertensive rats: 1-citrulline and nitrate," Translational Research, vol. 163, no. 1, pp. 43-52, 2014.

[86] K. M. Holmström, L. Baird, Y. Zhang et al., "Nrf2 impacts cellular bioenergetics by controlling substrate availability for mitochondrial respiration," Biology Open, vol. 2, no. 8, pp. 761-770, 2013.

[87] S. Wang, X. Zhu, L. Xiong, and J. Ren, "Ablation of Akt2 prevents paraquat-induced myocardial mitochondrial injury and contractile dysfunction: role of Nrf2," Toxicology Letters, vol. 269, pp. 1-14, 2017.

[88] Z. Liu, L. Sun, L. Zhu et al., "Hydroxytyrosol protects retinal pigment epithelial cells from acrolein-induced oxidative stress and mitochondrial dysfunction," Journal of Neurochemistry, vol. 103, no. 6, pp. 2690-2700, 2007.

[89] X. Zou, J. Gao, Y. Zheng et al., "Zeaxanthin induces Nrf2mediated phase II enzymes in protection of cell death," Cell Death \& Disease, vol. 5, article e1218, 2014.

[90] P. R. Coleman, G. Chang, G. Hutas, M. Grimshaw, M. A. Vadas, and J. R. Gamble, "Age-associated stresses induce an anti-inflammatory senescent phenotype in endothelial cells," Aging (Albany NY), vol. 5, no. 12, pp. 913-924, 2013.

[91] M. J. Crabtree, A. B. Hale, and K. M. Channon, "Dihydrofolate reductase protects endothelial nitric oxide synthase from uncoupling in tetrahydrobiopterin deficiency," Free Radical Biology and Medicine, vol. 50, no. 11, pp. 16391646, 2011.

[92] R. Carnicer, M. J. Crabtree, V. Sivakumaran, B. Casadei, and D. A. Kass, "Nitric oxide synthases in heart failure," Antioxidants \& Redox Signaling, vol. 18, no. 9, pp. 1078-1099, 2013.

[93] M. H. Zou, C. Shi, and R. A. Cohen, "Oxidation of the zincthiolate complex and uncoupling of endothelial nitric oxide synthase by peroxynitrite," The Journal of Clinical Investigation, vol. 109, no. 6, pp. 817-826, 2002.

[94] S. S. Soskic, B. D. Dobutovic, E. M. Sudar et al., "Regulation of inducible nitric oxide synthase (iNOS) and its potential role in insulin resistance, diabetes and heart failure," Open Cardiovascular Medicine Journal, vol. 5, pp. 153-163, 2011.

[95] D. Tousoulis, C. Antoniades, C. Tentolouris, G. Goumas, C. Stefanadis, and P. Toutouzas, "L-arginine in cardiovascular disease: dream or reality?, Vascular Medicine, vol. 7, no. 3, pp. 203-211, 2002.

[96] C. Zhang, T. W. Hein, W. Wang et al., "Upregulation of vascular arginase in hypertension decreases nitric oxidemediated dilation of coronary arterioles," Hypertension, vol. 44, no. 6, pp. 935-943, 2004.

[97] S. Chandra, M. J. Romero, A. Shatanawi, A. M. Alkilany, R. B. Caldwell, and R. W. Caldwell, "Oxidative species increase arginase activity in endothelial cells through the RhoA/Rho kinase pathway," British Journal of Pharmacology, vol. 165, no. 2, pp. 506-519, 2012.

[98] M. J. Romero, D. H. Platt, H. E. Tawfik et al., "Diabetesinduced coronary vascular dysfunction involves increased arginase activity," Circulation Research, vol. 102, no. 1, pp. 95-102, 2008.

[99] U. Forstermann and H. Li, "Therapeutic effect of enhancing endothelial nitric oxide synthase (eNOS) expression and preventing eNOS uncoupling," British Journal of Pharmacology, vol. 164, no. 2, pp. 213-223, 2011.

[100] J. S. Chen, P. H. Huang, C. H. Wang et al., "Nrf-2 mediated heme oxygenase- 1 expression, an antioxidant-independent mechanism, contributes to anti-atherogenesis and vascular protective effects of Ginkgo biloba extract," Atherosclerosis, vol. 214, no. 2, pp. 301-309, 2011.

[101] L. H. Chen, Q. Huang, L. Wan et al., "Expression, purification, and in vitro refolding of a humanized single-chain Fv antibody against human CTLA4 (CD152)," Protein Expression and Purification, vol. 46, no. 2, pp. 495-502, 2006.

[102] T. Hosoya, A. Maruyama, M. I. Kang et al., "Differential responses of the Nrf2-Keap1 system to laminar and oscillatory shear stresses in endothelial cells," The Journal of Biological Chemistry, vol. 280, no. 29, pp. 27244-27250, 2005.

[103] X. Cheng, R. C. Siow, and G. E. Mann, "Impaired redox signaling and antioxidant gene expression in endothelial cells in diabetes: a role for mitochondria and the nuclear factorE2-related factor 2-Kelch-like ECH-associated protein 1 defense pathway," Antioxidants \& Redox Signaling, vol. 14, no. 3, pp. 469-487, 2011.

[104] A. M. Mahmoud, F. L. Wilkinson, A. M. Jones et al., "A novel role for small molecule glycomimetics in the protection against lipid-induced endothelial dysfunction: involvement of Akt/eNOS and Nrf2/ARE signaling," Biochimica et Biophysica Acta (BBA) - General Subjects, vol. 1861, no. 1, Part A, pp. 3311-3322, 2017.

[105] H. L. Yang, M. Korivi, M. W. Lin, S. C. Chen, C. W. Chou, and Y. C. Hseu, "Anti-angiogenic properties of coenzyme $\mathrm{Q}_{0}$ through downregulation of MMP-9/NF- $\kappa \mathrm{B}$ and upregulation of HO-1 signaling in TNF- $\alpha$-activated human endothelial cells," Biochemical Pharmacology, vol. 98, no. 1, pp. 144-156, 2015.

[106] S. C. Lo and M. Hannink, "PGAM5 tethers a ternary complex containing Keap1 and Nrf2 to mitochondria," Experimental Cell Research, vol. 314, no. 8, pp. 1789-1803, 2008.

[107] J. Song, S. M. Kang, W. T. Lee, K. A. Park, K. M. Lee, and J. E. Lee, "Glutathione protects brain endothelial cells from hydrogen peroxide-induced oxidative stress by increasing nrf2 expression," Experimental Neurobiology, vol. 23, no. 1, pp. 93-103, 2014.

[108] Q. Zhong, M. Mishra, and R. A. Kowluru, "Transcription factor Nrf2-mediated antioxidant defense system in the development of diabetic retinopathy," Investigative Ophthalmology \& Visual Science, vol. 54, no. 6, pp. 3941-3948, 2013.

[109] H. G. Zhou, L. Liu, Y. Zhang et al., "Glutathione prevents free fatty acids-induced oxidative stress and apoptosis in human brain vascular endothelial cells through Akt pathway," CNS Neuroscience \& Therapeutics, vol. 19, no. 4, pp. 252-261, 2013.

[110] C. M. Warboys, N. Amini, A. d. Luca, and P. C. Evans, "The role of blood flow in determining the sites of atherosclerotic plaques," F1000 Medicine Reports, vol. 3, p. 5, 2011.

[111] P. Nigro, J. Abe, and B. Berk, "Flow shear stress and atherosclerosis: a matter of site specificity," Antioxidants \& Redox Signaling, vol. 15, pp. 1405-1414, 2011.

[112] G. H. Dai, M. R. Kaazempur-Mofrad, S. Natarajan et al., "Distinct endothelial phenotypes evoked by arterial waveforms derived from atherosclerosis-susceptible and -resistant regions of human vasculature," Proceedings of the National Academy of Sciences of the United States of America, vol. 101, no. 41, pp. 14871-14876, 2004. 
[113] J. J. Wentzel, Y. S. Chatzizisis, F. J. H. Gijsen, G. D. Giannoglou, C. L. Feldman, and P. H. Stone, "Endothelial shear stress in the evolution of coronary atherosclerotic plaque and vascular remodelling: current understanding and remaining questions," Cardiovascular Research, vol. 96, no. 2, pp. 234-243, 2012.

[114] L. Nayak, Z. Lin, and M. K. Jain, "“Go with the flow”: how Krüppel-like factor 2 regulates the vasoprotective effects of shear stress," Antioxidants \& Redox Signaling, vol. 15, no. 5, pp. 1449-1461, 2011.

[115] W. Takabe, E. Warabi, and N. Noguchi, "Anti-atherogenic effect of laminar shear stress via Nrf2 activation," Antioxidants \& Redox Signaling, vol. 15, pp. 1415-1426, 2011.

[116] M. Zakkar, K. Van der Heiden, L. A. Luong et al., “Activation of $\mathrm{Nrf} 2$ in endothelial cells protects arteries from exhibiting a proinflammatory state," Arteriosclerosis, Thrombosis, and Vascular Biology, vol. 29, no. 11, pp. 1851-1857, 2009.

[117] J. A. Araujo, M. Zhang, and F. Yin, "Heme oxygenase-1, oxidation, inflammation and atherosclerosis," Frontiers in Pharmacology, vol. 3, p. 119, 2012.

[118] S.-F. Yet, M. D. Layne, X. Liu et al., "Absence of heme oxygenase-1 exacerbates atherosclerotic lesion formation and vascular remodeling," The FASEB Journal, vol. 17, no. 12, pp. 1759-1761, 2003.

[119] L. D. Orozco, M. H. Kapturczak, B. Barajas et al., "Heme oxygenase-1 expression in macrophages plays a beneficial role in atherosclerosis," Circulation Research, vol. 100, no. 12, pp. 1703-1711, 2007.

[120] K. Ishikawa, D. Sugawara, X.-p. Wang et al., "Heme oxygenase-1 inhibits atherosclerotic lesion formation in LDL-receptor knockout mice," Circulation Research, vol. 88, no. 5, pp. 506-512, 2001.

[121] C. Cheng, A. M. Noordeloos, V. Jeney et al., "Heme oxygenase 1 determines atherosclerotic lesion progression into a vulnerable plaque," Circulation, vol. 119, no. 23, pp. 30173027, 2009.

[122] L. Xie, Y. Gu, M. Wen et al., "Hydrogen sulfide induces Keap1 S-sulfhydration and suppresses diabetes-accelerated atherosclerosis via Nrf2 activation," Diabetes, vol. 65, no. 10, pp. 3171-3184, 2016.

[123] B. Barajas, N. Che, F. Yin et al., "NF-E2-related factor 2 promotes atherosclerosis by effects on plasma lipoproteins and cholesterol transport that overshadow antioxidant protection," Arteriosclerosis, Thrombosis, and Vascular Biology, vol. 31, no. 1, pp. 58-66, 2011.

[124] T. E. Sussan, J. Jun, R. Thimmulappa et al., "Disruption of Nrf2, a key inducer of antioxidant defenses, attenuates ApoE-mediated atherosclerosis in mice," PLoS One, vol. 3, no. 11, article e3791, 2008.

[125] S. Freigang, F. Ampenberger, G. Spohn et al., "Nrf2 is essential for cholesterol crystal-induced inflammasome activation and exacerbation of atherosclerosis," European Journal of Immunology, vol. 41, no. 7, pp. 2040-2051, 2011.

[126] P. Zhang, Y. Li, Y. Du, G. Li, L. Wang, and F. Zhou, "Resveratrol ameliorated vascular calcification by regulating Sirt-1 and Nrf2," Transplantation Proceedings, vol. 48, no. 10, pp. 3378-3386, 2016.

[127] C.-M. Ha, S. Park, Y.-K. Choi et al., "Activation of Nrf2 by dimethyl fumarate improves vascular calcification," Vascular Pharmacology, vol. 63, no. 1, pp. 29-36, 2014.
[128] H.-J. Sim, J.-H. Kim, S.-H. Kook, S.-Y. Lee, and J.-C. Lee, "Glucose oxidase facilitates osteogenic differentiation and mineralization of embryonic stem cells through the activation of Nrf2 and ERK signal transduction pathways," Molecular and Cellular Biochemistry, vol. 419, no. 1, pp. 157-163, 2016.

[129] A. Benigni, P. Cassis, and G. Remuzzi, "Angiotensin II revisited: new roles in inflammation, immunology and aging," EMBO Molecular Medicine, vol. 2, no. 7, pp. 247257, 2010.

[130] P. K. Mehta and K. K. Griendling, “Angiotensin II cell signaling: physiological and pathological effects in the cardiovascular system," American Journal of Physiology-Cell Physiology, vol. 292, no. 1, pp. C82-C97, 2007.

[131] C. Delles, W. H. Miller, and A. F. Dominiczak, "Targeting reactive oxygen species in hypertension," Antioxidants \& Redox Signaling, vol. 10, no. 6, pp. 1061-1078, 2008.

[132] E. Grossman, "Does increased oxidative stress cause hypertension?," Diabetes Care, vol. 31, Supplement 2, pp. S185S189, 2008.

[133] R. A. Lopes, K. B. Neves, R. C. Tostes, A. C. Montezano, and R. M. Touyz, "Downregulation of nuclear factor erythroid 2-related factor and associated antioxidant genes contributes to redox-sensitive vascular dysfunction in hypertension," Hypertension, vol. 66, no. 6, pp. 1240-1250, 2015.

[134] Y. Chen, J. T. Saari, and Y. J. Kang, "Weak antioxidant defenses make the heart a target for damage in copperdeficient rats," Free Radical Biology and Medicine, vol. 17, no. 6, pp. 529-536, 1994.

[135] A. F. Amos, D. J. McCarty, and P. Zimmet, "The rising global burden of diabetes and its complications: estimates and projections to the year 2010," Diabetic Medicine, vol. 14, Supplement 5, pp. S1-85, 1997.

[136] K. Huynh, B. C. Bernardo, J. R. McMullen, and R. H. Ritchie, "Diabetic cardiomyopathy: mechanisms and new treatment strategies targeting antioxidant signaling pathways," Pharmacology \& Therapeutics, vol. 142, no. 3, pp. 375-415, 2014.

[137] S. Boudina and E. D. Abel, "Diabetic cardiomyopathy revisited," Circulation, vol. 115, no. 25, pp. 3213-3223, 2007.

[138] L. Cai and Y. J. Kang, "Oxidative stress and diabetic cardiomyopathy: a brief review," Cardiovascular Toxicology, vol. 1, no. 3, pp. 181-193, 2001.

[139] L. Cai, Y. Wang, G. Zhou et al., “Attenuation by metallothionein of early cardiac cell death via suppression of mitochondrial oxidative stress results in a prevention of diabetic cardiomyopathy," Journal of the American College of Cardiology, vol. 48, no. 8, pp. 1688-1697, 2006.

[140] M. Hamblin, D. B. Friedman, S. Hill, R. M. Caprioli, H. M. Smith, and M. F. Hill, "Alterations in the diabetic myocardial proteome coupled with increased myocardial oxidative stress underlies diabetic cardiomyopathy," Journal of Molecular and Cellular Cardiology, vol. 42, no. 4, pp. 884-895, 2007.

[141] Y. Kayama, U. Raaz, A. Jagger et al., "Diabetic cardiovascular disease induced by oxidative stress," International Journal of Molecular Sciences, vol. 16, no. 10, pp. 25234-25263, 2015.

[142] T. Inoguchi, P. Li, F. Umeda et al., "High glucose level and free fatty acid stimulate reactive oxygen species production through protein kinase C-dependent activation of $\mathrm{NAD}(\mathrm{P}) \mathrm{H}$ oxidase in cultured vascular cells," Diabetes, vol. 49, no. 11, pp. 1939-1945, 2000. 
[143] P. Gao, L. Li, L. Ji et al., "Nrf2 ameliorates diabetic nephropathy progression by transcriptional repression of TGF $\beta 1$ through interactions with c-Jun and SP1," Biochimica et Biophysica Acta, vol. 1839, no. 11, pp. 1110-1120, 2014.

[144] Z. Xu, Y. Wei, J. Gong et al., "NRF2 plays a protective role in diabetic retinopathy in mice," Diabetologia, vol. 57, no. 1 , pp. 204-213, 2014.

[145] H. Zhu, K. Itoh, M. Yamamoto, J. L. Zweier, and Y. Li, "Role of Nrf2 signaling in regulation of antioxidants and phase 2 enzymes in cardiac fibroblasts: protection against reactive oxygen and nitrogen species-induced cell injury," FEBS Letters, vol. 579, no. 14, pp. 3029-3036, 2005.

[146] P. V. Dludla, C. J. Muller, E. Joubert et al., "Aspalathin protects the heart against hyperglycemia-induced oxidative damage by up-regulating Nrf2 expression," Molecules, vol. 22, no. 1, 2017.

[147] Y. Tan, T. Ichikawa, J. Li et al., "Diabetic downregulation of Nrf2 activity via ERK contributes to oxidative stressinduced insulin resistance in cardiac cells in vitro and in vivo," Diabetes, vol. 60, no. 2, pp. 625-633, 2011.

[148] B. Li, S. Liu, L. Miao, and L. Cai, "Prevention of diabetic complications by activation of Nrf2: diabetic cardiomyopathy and nephropathy," Experimental Diabetes Research, vol. 2012, Article ID 216512, 7 pages, 2012.

[149] L. Cai, J. Wang, Y. Li et al., "Inhibition of superoxide generation and associated nitrosative damage is involved in metallothionein prevention of diabetic cardiomyopathy," Diabetes, vol. 54, no. 6, pp. 1829-1837, 2005.

[150] Y. Wang, W. Feng, W. Xue et al., "Inactivation of GSK-3 $\beta$ by metallothionein prevents diabetes-related changes in cardiac energy metabolism, inflammation, nitrosative damage, and remodeling," Diabetes, vol. 58, no. 6, pp. 1391-1402, 2009.

[151] X. He, H. Kan, L. Cai, and Q. Ma, "Nrf2 is critical in defense against high glucose-induced oxidative damage in cardiomyocytes," Journal of Molecular and Cellular Cardiology, vol. 46, no. 1, pp. 47-58, 2009.

[152] J. Li, T. Ichikawa, L. Villacorta et al., "Nrf2 Protects Against Maladaptive Cardiac Responses to Hemodynamic stress," Arteriosclerosis, Thrombosis, and Vascular Biology, vol. 29, no. 11, pp. 1843-1850, 2009.

[153] Y. Wang, W. Sun, B. Du et al., "Therapeutic effect of MG-132 on diabetic cardiomyopathy is associated with its suppression of proteasomal activities: roles of Nrf2 and NF- $\kappa \mathrm{B}$," The American Journal of Physiology-Heart and Circulatory Physiology, vol. 304, no. 4, pp. H567-H578, 2013.

[154] Y. Bai, W. Cui, Y. Xin et al., "Prevention by sulforaphane of diabetic cardiomyopathy is associated with up-regulation of Nrf2 expression and transcription activation," Journal of Molecular and Cellular Cardiology, vol. 57, pp. 82-95, 2013.

[155] L. Cai, "Diabetic cardiomyopathy and its prevention by metallothionein: experimental evidence, possible mechanisms and clinical implications," Current Medicinal Chemistry, vol. 14, no. 20, pp. 2193-2203, 2007.

[156] C. Lopez-Otin, M. A. Blasco, L. Partridge, M. Serrano, and G. Kroemer, "The hallmarks of aging," Cell, vol. 153, no. 6, pp. 1194-1217, 2013.

[157] H. E. Wheeler and S. K. Kim, "Genetics and genomics of human ageing," Philosophical Transactions of the Royal Society of London. Series B, Biological Sciences, vol. 366, no. 1561 , pp. $43-50,2011$.
[158] M. Wang, J. Zhang, S. J. Walker, R. Dworakowski, E. G. Lakatta, and A. M. Shah, "Involvement of NADPH oxidase in age-associated cardiac remodeling," Journal of Molecular and Cellular Cardiology, vol. 48, no. 4, pp. 765-772, 2010.

[159] D. Harman, "Aging: a theory based on free radical and radiation chemistry," Journal of Gerontology, vol. 11, no. 3, pp. 298-300, 1956.

[160] N. Poulose and R. Raju, "Aging and injury: alterations in cellular energetics and organ function," Aging and Disease, vol. 5, no. 2, pp. 101-108, 2014.

[161] A. Silva-Palacios, M. Konigsberg, and C. Zazueta, "Nrf2 signaling and redox homeostasis in the aging heart: a potential target to prevent cardiovascular diseases?," Ageing Research Reviews, vol. 26, pp. 81-95, 2016.

[162] R. Foncea, C. Carvajal, C. Almarza, and F. Leighton, "Endothelial cell oxidative stress and signal transduction," Biological Research, vol. 33, no. 2, pp. 89-96, 2000.

[163] M. Michaud, L. Balardy, G. Moulis et al., "Proinflammatory cytokines, aging, and age-related diseases," Journal of the American Medical Directors Association, vol. 14, no. 12, pp. 877-882, 2013.

[164] A. Manea, S. A. Manea, A. V. Gafencu, and M. Raicu, "Regulation of NADPH oxidase subunit $\mathrm{p} 22^{\text {phox }}$ by NF-kB in human aortic smooth muscle cells," Archives of Physiology and Biochemistry, vol. 113, no. 4-5, pp. 163-172, 2007.

[165] M. El Assar, J. Angulo, and L. Rodriguez-Manas, "Oxidative stress and vascular inflammation in aging," Free Radical Biology and Medicine, vol. 65, pp. 380-401, 2013.

[166] A. J. Donato, R. G. Morgan, A. E. Walker, and L. A. Lesniewski, "Cellular and molecular biology of aging endothelial cells," Journal of Molecular and Cellular Cardiology, vol. 89, Part B, pp. 122-135, 2015.

[167] A. J. Donato, I. Eskurza, A. E. Silver et al., "Direct evidence of endothelial oxidative stress with aging in humans: relation to impaired endothelium-dependent dilation and upregulation of nuclear factor- $\kappa \mathrm{B}$," Circulation Research, vol. 100, no. 11, pp. 1659-1666, 2007.

[168] B. J. North and D. A. Sinclair, "The intersection between aging and cardiovascular disease," Circulation Research, vol. 110, no. 8, pp. 1097-1108, 2012.

[169] D. F. Goldspink, J. G. Burniston, and L. B. Tan, "Cardiomyocyte death and the ageing and failing heart," Experimental Physiology, vol. 88, no. 3, pp. 447-458, 2003.

[170] S. Boudina, "Cardiac aging and insulin resistance: could insulin/insulin-like growth factor (IGF) signaling be used as a therapeutic target?," Current Pharmaceutical Design, vol. 19, no. 32, pp. 5684-5694, 2013.

[171] J. B. Strait and E. G. Lakatta, "Aging-associated cardiovascular changes and their relationship to heart failure," Heart Failure Clinics, vol. 8, no. 1, pp. 143-164, 2012.

[172] H. B. Kwak, "Aging, exercise, and extracellular matrix in the heart," Journal of Exercise Rehabilitation, vol. 9, no. 3, pp. 338-347, 2013.

[173] A. Frank, M. Bonney, S. Bonney, L. Weitzel, M. Koeppen, and T. Eckle, "Myocardial ischemia reperfusion injury: from basic science to clinical bedside," Seminars in Cardiothoracic and Vascular Anesthesia, vol. 16, no. 3, pp. 123132, 2012.

[174] A. M. Walters, G. A. Porter Jr., and P. S. Brookes, "Mitochondria as a drug target in ischemic heart disease and 
cardiomyopathy," Circulation Research, vol. 111, no. 9, pp. 1222-1236, 2012.

[175] A. M. Orogo and A. B. Gustafsson, "Cell death in the myocardium: my heart won't go on," IUBMB Life, vol. 65, no. 8, pp. 651-656, 2013.

[176] A. Boning, S. Rohrbach, L. Kohlhepp et al., "Differences in ischemic damage between young and old hearts-effects of blood cardioplegia," Experimental Gerontology, vol. 67, pp. 3-8, 2015.

[177] O. M. Duicu, S. N. Mirica, D. E. Gheorgheosu, A. I. Privistirescu, O. Fira-Mladinescu, and D. M. Muntean, "Ageing-induced decrease in cardiac mitochondrial function in healthy rats," Canadian Journal of Physiology and Pharmacology, vol. 91, no. 8, pp. 593-600, 2013.

[178] J. Kajstura, W. Cheng, R. Sarangarajan et al., "Necrotic and apoptotic myocyte cell death in the aging heart of Fischer 344 rats," The American Journal of Physiology, vol. 271, no. 3, Part 2, pp. H1215-H1228, 1996.

[179] M. N. Valcarcel-Ares, T. Gautam, J. P. Warrington et al., "Disruption of Nrf2 signaling impairs angiogenic capacity of endothelial cells: implications for microvascular aging," The Journals of Gerontology. Series A, Biological Sciences and Medical Sciences, vol. 67, no. 8, pp. 821-829, 2012.

[180] S. Zhou, W. Sun, Z. Zhang, and Y. Zheng, "The role of Nrf2mediated pathway in cardiac remodeling and heart failure," Oxidative Medicine and Cellular Longevity, vol. 2014, Article ID 260429, 16 pages, 2014.

[181] L. C. Bailey-Downs, M. Mitschelen, D. Sosnowska et al., "Liver-specific knockdown of IGF-1 decreases vascular oxidative stress resistance by impairing the Nrf2-dependent antioxidant response: a novel model of vascular aging," The Journals of Gerontology. Series A, Biological Sciences and Medical Sciences, vol. 67, no. 4, pp. 313-329, 2012.

[182] J. Li, C. Zhang, Y. Xing et al., "Up-regulation of p27 $7^{\mathrm{kip} 1}$ contributes to Nrf2-mediated protection against angiotensin II-induced cardiac hypertrophy," Cardiovascular Research, vol. 90, no. 2, pp. 315-324, 2011.

[183] Z. Ungvari, L. Bailey-Downs, D. Sosnowska et al., "Vascular oxidative stress in aging: a homeostatic failure due to dysregulation of NRF2-mediated antioxidant response," American Journal of Physiology. Heart and Circulatory Physiology, vol. 301, no. 2, pp. H363-H372, 2011.

[184] V. R. Muthusamy, S. Kannan, K. Sadhaasivam et al., "Acute exercise stress activates Nrf2/ARE signaling and promotes antioxidant mechanisms in the myocardium," Free Radical Biology and Medicine, vol. 52, no. 2, pp. 366-376, 2012.

[185] S. S. Gounder, S. Kannan, D. Devadoss et al., "Impaired transcriptional activity of Nrf2 in age-related myocardial oxidative stress is reversible by moderate exercise training," PLLoS One, vol. 7, no. 9, article e45697, 2012.

[186] J. R. Stratton, W. C. Levy, M. D. Cerqueira, R. S. Schwartz, and I. B. Abrass, "Cardiovascular responses to exercise. Effects of aging and exercise training in healthy men," Circulation, vol. 89, no. 4, pp. 1648-1655, 1994.

[187] S. Wang, Y. Li, X. Song et al., "Febuxostat pretreatment attenuates myocardial ischemia/reperfusion injury via mitochondrial apoptosis," Journal of Translational Medicine, vol. 13, p. 209, 2015.

[188] A. Sharma, L. Rizky, N. Stefanovic et al., "The nuclear factor (erythroid-derived 2)-like 2 (Nrf2) activator dh404 protects against diabetes-induced endothelial dysfunction," Cardiovascular Diabetology, vol. 16, no. 1, p. 33, 2017.

[189] S. M. Tan, A. Sharma, N. Stefanovic et al., "Derivative of bardoxolone methyl, dh404, in an inverse dose-dependent manner lessens diabetes-associated atherosclerosis and improves diabetic kidney disease," Diabetes, vol. 63, no. 9, pp. 3091-3103, 2014.

[190] N. M. Shawky and L. Segar, "Sulforaphane inhibits plateletderived growth factor-induced vascular smooth muscle cell proliferation by targeting mTOR/p70S6kinase signaling independent of Nrf2 activation," Pharmacological Research, vol. 119, pp. 251-264, 2017.

[191] C. S. Huang, A. H. Lin, C. T. Liu et al., "Isothiocyanates protect against oxidized LDL-induced endothelial dysfunction by upregulating Nrf2-dependent antioxidation and suppressing NF $\kappa$ B activation," Molecular Nutrition \& Food Research, vol. 57, no. 11, pp. 1918-1930, 2013.

[192] Y. Wang, Z. Zhang, W. Sun et al., "Sulforaphane attenuation of type 2 diabetes-induced aortic damage was associated with the upregulation of Nrf2 expression and function," Oxidative Medicine and Cellular Longevity, vol. 2014, Article ID 123963, 11 pages, 2014.

[193] X. Miao, Y. Bai, W. Sun et al., "Sulforaphane prevention of diabetes-induced aortic damage was associated with the up-regulation of Nrf2 and its down-stream antioxidants," Nutrition \& Metabolism (London), vol. 9, no. 1, p. 84, 2012.

[194] L. Zhang, H. Zhang, X. Li et al., "Miltirone protects human EA.hy926 endothelial cells from oxidized low-density lipoprotein-derived oxidative stress via a heme oxygenase-1 and MAPK/Nrf2 dependent pathway," Phytomedicine, vol. 23, no. 14, pp. 1806-1813, 2016.

[195] G. Z. Yang, Z. J. Wang, F. Bai et al., "Epigallocatechin-3-gallate protects HUVECs from PM2.5-induced oxidative stress injury by activating critical antioxidant pathways," Molecules, vol. 20, no. 4, pp. 6626-6639, 2015.

[196] D. R. Senger, M. V. Hoang, K. H. Kim, C. Li, and S. Cao, "Anti-inflammatory activity of Barleria lupulina: identification of active compounds that activate the Nrf2 cell defense pathway, organize cortical actin, reduce stress fibers, and improve cell junctions in microvascular endothelial cells," Journal of Ethnopharmacology, vol. 193, pp. 397-407, 2016.

[197] M. M. Sthijns, P. M. Schiffers, G. M. Janssen et al., "Rutin protects against $\mathrm{H}_{2} \mathrm{O}_{2}$-triggered impaired relaxation of placental arterioles and induces Nrf2-mediated adaptation in human umbilical vein endothelial cells exposed to oxidative stress," Biochimica et Biophysica Acta (BBA) - General Subjects, vol. 1861, no. 5, Part A, pp. 1177-1189, 2017.

[198] T. M. Teixeira, D. C. da Costa, A. C. Resende, C. O. Soulage, F. F. Bezerra, and J. B. Daleprane, "Activation of Nrf2antioxidant signaling by 1,25-dihydroxycholecalciferol prevents leptin-induced oxidative stress and inflammation in human endothelial cells," The Journal of Nutrition, vol. 147, no. 4, pp. 506-513, 2017.

[199] A. Ishikado, Y. Sono, M. Matsumoto et al., "Willow bark extract increases antioxidant enzymes and reduces oxidative stress through activation of Nrf2 in vascular endothelial cells and Caenorhabditis elegans," Free Radical Biology and Medicine, vol. 65, pp. 1506-1515, 2013.

[200] K. Hiramatsu, T. Tsuneyoshi, T. Ogawa, and N. Morihara, "Aged garlic extract enhances heme oxygenase-1 and glutamate-cysteine ligase modifier subunit expression via 
the nuclear factor erythroid 2-related factor 2-antioxidant response element signaling pathway in human endothelial cells," Nutrition Research, vol. 36, no. 2, pp. 143-149, 2016.

[201] M. Li, X. Liu, Y. He et al., "Celastrol attenuates angiotensin II mediated human umbilical vein endothelial cells damage through activation of Nrf2/ERK1/2/Nox2 signal pathway," European Journal of Pharmacology, vol. 797, pp. 124-133, 2017.

[202] D. H. Kim, S. M. Lee, Y. J. Lee et al., "Effect of Paeotang on tumor necrosis factor alpha-induced vascular inflammation in human umbilical vein endothelial cells," Chinese Journal of Integrative Medicine, pp. 1-10, 2017.

[203] D. Fratantonio, F. Cimino, M. S. Molonia et al., "Cyanidin-3$\mathrm{O}$-glucoside ameliorates palmitate-induced insulin resistance by modulating IRS-1 phosphorylation and release of endothelial derived vasoactive factors," Biochimica et Biophysica Acta, vol. 1862, no. 3, pp. 351-357, 2017.

[204] D. Fratantonio, A. Speciale, D. Ferrari, M. Cristani, A. Saija, and F. Cimino, "Palmitate-induced endothelial dysfunction is attenuated by cyanidin-3-O-glucoside through modulation of Nrf2/Bach1 and NF- $\kappa \mathrm{B}$ pathways," Toxicology Letters, vol. 239, no. 3, pp. 152-160, 2015.

[205] S. Sivasinprasasn, R. Pantan, S. Thummayot, J. Tocharus, A. Suksamrarn, and C. Tocharus, "Cyanidin-3-glucoside attenuates angiotensin II-induced oxidative stress and inflammation in vascular endothelial cells," Chemico-Biological Interactions, vol. 260, pp. 67-74, 2016.

[206] J. S. Kil, S. O. Jeong, H. T. Chung, and H. O. Pae, "Piceatannol attenuates homocysteine-induced endoplasmic reticulum stress and endothelial cell damage via heme oxygenase-1 expression," Amino Acids, vol. 49, no. 4, pp. 735-745, 2017.

[207] T. Zhang, Q. Hu, L. Shi, L. Qin, Q. Zhang, and M. Mi, "Equol attenuates atherosclerosis in apolipoprotein E-deficient mice by inhibiting endoplasmic reticulum stress via activation of Nrf2 in endothelial cells," PLoS One, vol. 11, no. 12, article e0167020, 2016.

[208] E. Kerasioti, D. Stagos, A. Tzimi, and D. Kouretas, "Increase in antioxidant activity by sheep/goat whey protein through nuclear factor-like 2 (Nrf2) is cell type dependent," Food and Chemical Toxicology, vol. 97, pp. 47-56, 2016.

[209] C. Li, W. J. Zhang, and B. Frei, "Quercetin inhibits LPSinduced adhesion molecule expression and oxidant production in human aortic endothelial cells by p38-mediated Nrf2 activation and antioxidant enzyme induction," Redox Biology, vol. 9, pp. 104-113, 2016.

[210] J. Fan, D. Liu, C. He, X. Li, and F. He, "Inhibiting adhesion events by Panax notoginseng saponins and Ginsenoside $\mathrm{Rb} 1$ protecting arteries via activation of $\mathrm{Nrf} 2$ and suppression of p38-VCAM-1 signal pathway," Journal of Ethnopharmacology, vol. 192, pp. 423-430, 2016.

[211] A. Sahni, E. D. Thomasson, R. Shah, and S. K. Sahni, "Bortezomib effects on human microvascular endothelium in vitro," Pharmacology, vol. 98, no. 5-6, pp. 272-278, 2016.

[212] K. Onda, S. Tong, A. Nakahara et al., "Sofalcone upregulates the nuclear factor (erythroid-derived 2)-like 2/heme oxygenase-1 pathway, reduces soluble fms-like tyrosine kinase-1, and quenches endothelial dysfunction: potential therapeutic for preeclampsia," Hypertension, vol. 65 , no. 4, pp. 855-862, 2015.

[213] Y. Zhu, Y. J. Zhang, W. W. Liu, A. W. Shi, and N. Gu, "Salidroside suppresses HUVECs cell injury induced by oxidative stress through activating the Nrf2 signaling pathway," Molecules, vol. 21, no. 8, 2016.

[214] D. Fratantonio, A. Speciale, R. Canali et al., "Low nanomolar caffeic acid attenuates high glucose-induced endothelial dysfunction in primary human umbilical-vein endothelial cells by affecting NF- $\kappa$ B and Nrf2 pathways," BioFactors, vol. 43, no. 1, pp. 54-62, 2017.

[215] B. Zhang, Y. Chen, Q. Shen et al., "Myricitrin attenuates high glucose-induced apoptosis through activating Akt-Nrf2 signaling in H9c2 cardiomyocytes," Molecules, vol. 21, no. 7, 2016.

[216] B. Zhang, Q. Shen, Y. Chen et al., "Myricitrin alleviates oxidative stress-induced inflammation and apoptosis and protects mice against diabetic cardiomyopathy," Scientific Reports, vol. 7, article 44239, 2017.

[217] H. C. Lin, S. L. Su, C. Y. Lu et al., "Andrographolide inhibits hypoxia-induced HIF- $1 \alpha$-driven endothelin 1 secretion by activating $\mathrm{Nrf} 2 / \mathrm{HO}-1$ and promoting the expression of prolyl hydroxylases $2 / 3$ in human endothelial cells," Environmental Toxicology, vol. 32, no. 3, pp. 918-930, 2017.

[218] S. Zhuang, T. H. Cheng, N. L. Shih et al., "Tanshinone IIA induces heme oxygenase 1 expression and inhibits cyclic strain-induced interleukin 8 expression in vascular endothelial cells," The American Journal of Chinese Medicine, vol. 44, no. 2, pp. 377-388, 2016.

[219] L. C. Sung, H. H. Chao, C. H. Chen et al., "Lycopene inhibits cyclic strain-induced endothelin-1 expression through the suppression of reactive oxygen species generation and induction of heme oxygenase- 1 in human umbilical vein endothelial cells," Clinical and Experimental Pharmacology \& Physiology, vol. 42, no. 6, pp. 632-639, 2015.

[220] K. Heyninck, L. Sabbe, C. S. Chirumamilla et al., "Withaferin A induces heme oxygenase (HO-1) expression in endothelial cells via activation of the Keap1/Nrf2 pathway," Biochemical Pharmacology, vol. 109, pp. 48-61, 2016.

[221] T. Fujie, M. Murakami, E. Yoshida et al., "Copper diethyldithiocarbamate as an activator of Nrf2 in cultured vascular endothelial cells," Journal of Biological Inorganic Chemistry, vol. 21, no. 2, pp. 263-273, 2016.

[222] H. Yang, P. Zhao, and S. Tian, "Clopidogrel protects endothelium by hindering $\mathrm{TNF} \alpha$-induced VCAM-1 expression through CaMKK $\beta / \mathrm{AMPK/Nrf2}$ pathway," Journal of Diabetes Research, vol. 2016, Article ID 9128050, 10 pages, 2016.

[223] H. C. Chang, H. L. Yang, J. H. Pan et al., "Hericium erinaceus inhibits TNF- $\alpha$-induced angiogenesis and ROS generation through suppression of MMP-9/NF- $\kappa$ B signaling and activation of Nrf2-mediated antioxidant genes in human EA.hy926 endothelial cells," Oxidative Medicine and Cellular Longevity, vol. 2016, Article ID 8257238, 15 pages, 2016.

[224] T. L. Yen, R. J. Chen, T. Jayakumar et al., "Andrographolide stimulates $\mathrm{p} 38$ mitogen-activated protein kinase-nuclear factor erythroid-2-related factor 2-heme oxygenase 1 signaling in primary cerebral endothelial cells for definite protection against ischemic stroke in rats," Translational Research, vol. 170, pp. 57-72, 2016.

[225] J. Duan, Y. Guan, F. Mu et al., "Protective effect of butin against ischemia/reperfusion-induced myocardial injury in diabetic mice: involvement of the AMPK/GSK- $3 \beta / \mathrm{Nrf} 2$ signaling pathway," Scientific Reports, vol. 7, article 41491, 2017.

[226] Z. Xu, S. Wang, H. Ji et al., "Broccoli sprout extract prevents diabetic cardiomyopathy via Nrf2 activation in $\mathrm{db} / \mathrm{db}$ T2DM mice," Scientific Reports, vol. 6, article 30252, 2016. 
[227] W. Sun, X. Wang, C. Hou et al., "Oleuropein improves mitochondrial function to attenuate oxidative stress by activating the Nrf2 pathway in the hypothalamic paraventricular nucleus of spontaneously hypertensive rats," Neuropharmacology, vol. 113, Part A, pp. 556-566, 2017.

[228] J. Duan, G. Wei, C. Guo et al., “Aralia taibaiensis protects cardiac myocytes against high glucose-induced oxidative stress and apoptosis," The American Journal of Chinese Medicine, vol. 43, no. 6, pp. 1159-1175, 2015.

[229] Y. Liu, Y. Wang, X. Miao et al., "Inhibition of JNK by compound C66 prevents pathological changes of the aorta in STZ-induced diabetes," Journal of Cellular and Molecular Medicine, vol. 18, no. 6, pp. 1203-1212, 2014.

[230] S. H. Choi, S. Park, C. J. Oh, J. Leem, K. G. Park, and I. K. Lee, "Dipeptidyl peptidase- 4 inhibition by gemigliptin prevents abnormal vascular remodeling via NF-E2-related factor 2 activation," Vascular Pharmacology, vol. 73, pp. 11-19, 2015.

[231] P. Zhong, L. Wu, Y. Qian et al., "Blockage of ROS and NF- $\kappa$ B-mediated inflammation by a new chalcone L6H9 protects cardiomyocytes from hyperglycemia-induced injuries," Biochimica et Biophysica Acta, vol. 1852, no. 7, pp. 1230-1241, 2015.

[232] K. Y. Hur, S. H. Kim, M. A. Choi et al., "Protective effects of magnesium lithospermate $\mathrm{B}$ against diabetic atherosclerosis via Nrf2-ARE-NQO1 transcriptional pathway," Atherosclerosis, vol. 211, no. 1, pp. 69-76, 2010.

[233] Z. Zhang, J. Chen, S. Zhou et al., "Magnolia bioactive constituent 4-O-methylhonokiol prevents the impairment of cardiac insulin signaling and the cardiac pathogenesis in high-fat diet-induced obese mice," International Journal of Biological Sciences, vol. 11, no. 8, pp. 879-891, 2015.

[234] Z. Ungvari, Z. Bagi, A. Feher et al., "Resveratrol confers endothelial protection via activation of the antioxidant transcription factor Nrf2," American Journal of Physiology. Heart and Circulatory Physiology, vol. 299, no. 1, pp. H18$\mathrm{H} 24,2010$.

[235] R. Guo, B. Liu, K. Wang, S. Zhou, W. Li, and Y. Xu, "Resveratrol ameliorates diabetic vascular inflammation and macrophage infiltration in $\mathrm{db} / \mathrm{db}$ mice by inhibiting the NF- $\kappa \mathrm{B}$ pathway," Diabetes \& Vascular Disease Research, vol. 11, no. 2, pp. 92-102, 2014.

[236] X. Zheng, S. Zhu, S. Chang et al., "Protective effects of chronic resveratrol treatment on vascular inflammatory injury in streptozotocin-induced type 2 diabetic rats: role of NFkappa B signaling," European Journal of Pharmacology, vol. 720, no. 1, pp. 147-157, 2013.

[237] X. Miao, W. Cui, W. Sun et al., "Therapeutic effect of MG132 on the aortic oxidative damage and inflammatory response in OVE26 type 1 diabetic mice," Oxidative Medicine and Cellular Longevity, vol. 2013, Article ID 879516, 12 pages, 2013.

[238] Y. Wang, W. Sun, B. Du et al., "Therapeutic effect of MG-132 on diabetic cardiomyopathy is associated with its suppression of proteasomal activities: roles of Nrf2 and NF- $\kappa \mathrm{B}$," American Journal of Physiology-Heart and Circulatory Physiology, vol. 304, no. 4, pp. H567-H578, 2013. 


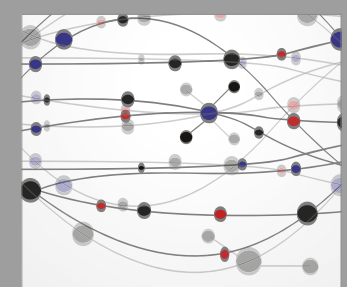

The Scientific World Journal
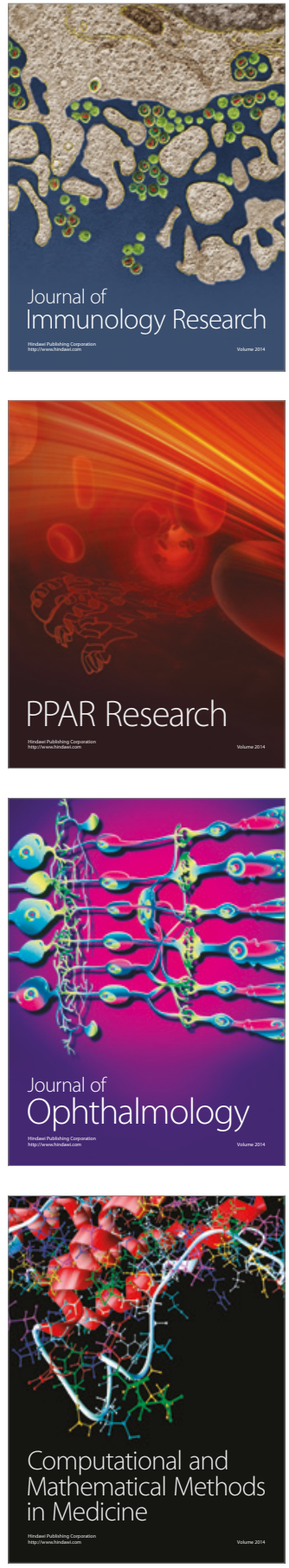

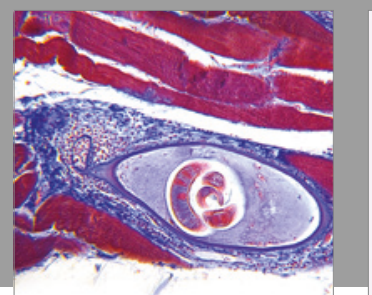

Gastroenterology Research and Practice
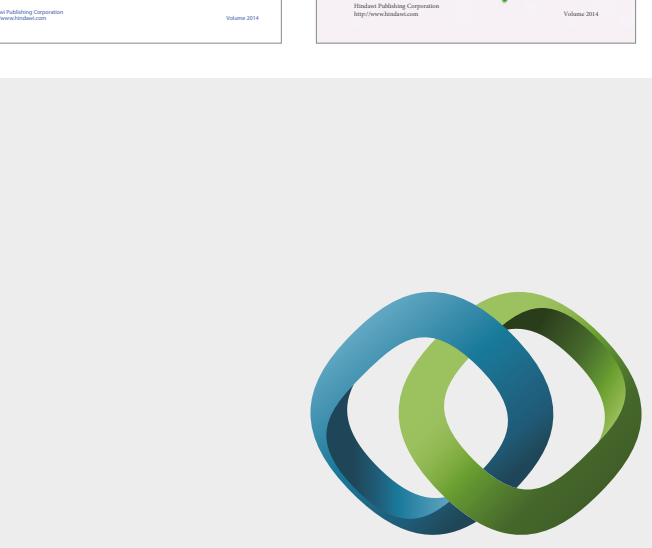

\section{Hindawi}

Submit your manuscripts at

https://www.hindawi.com
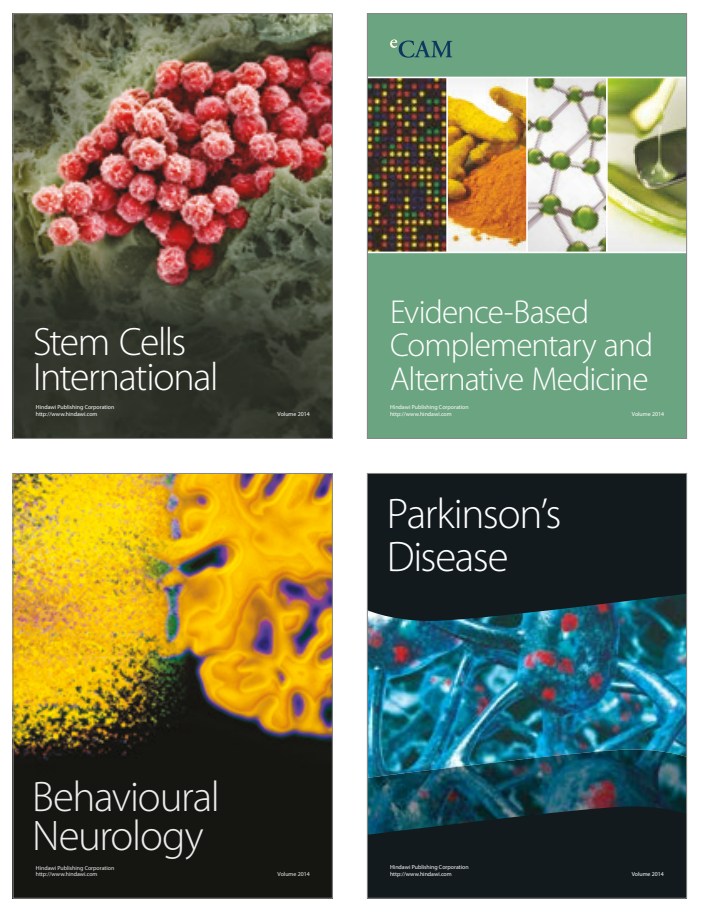
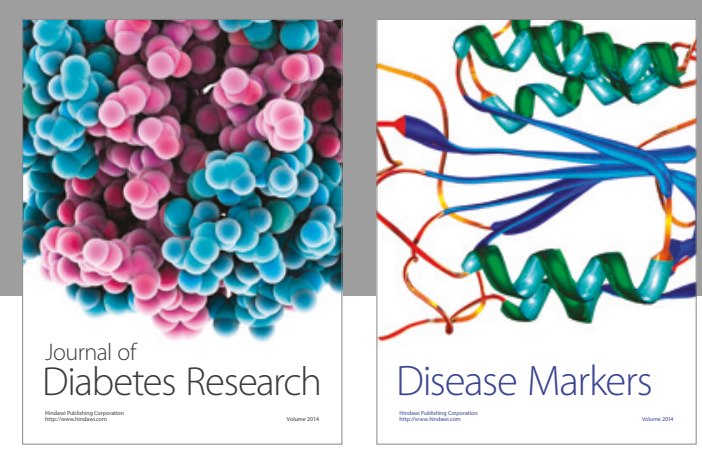

Disease Markers
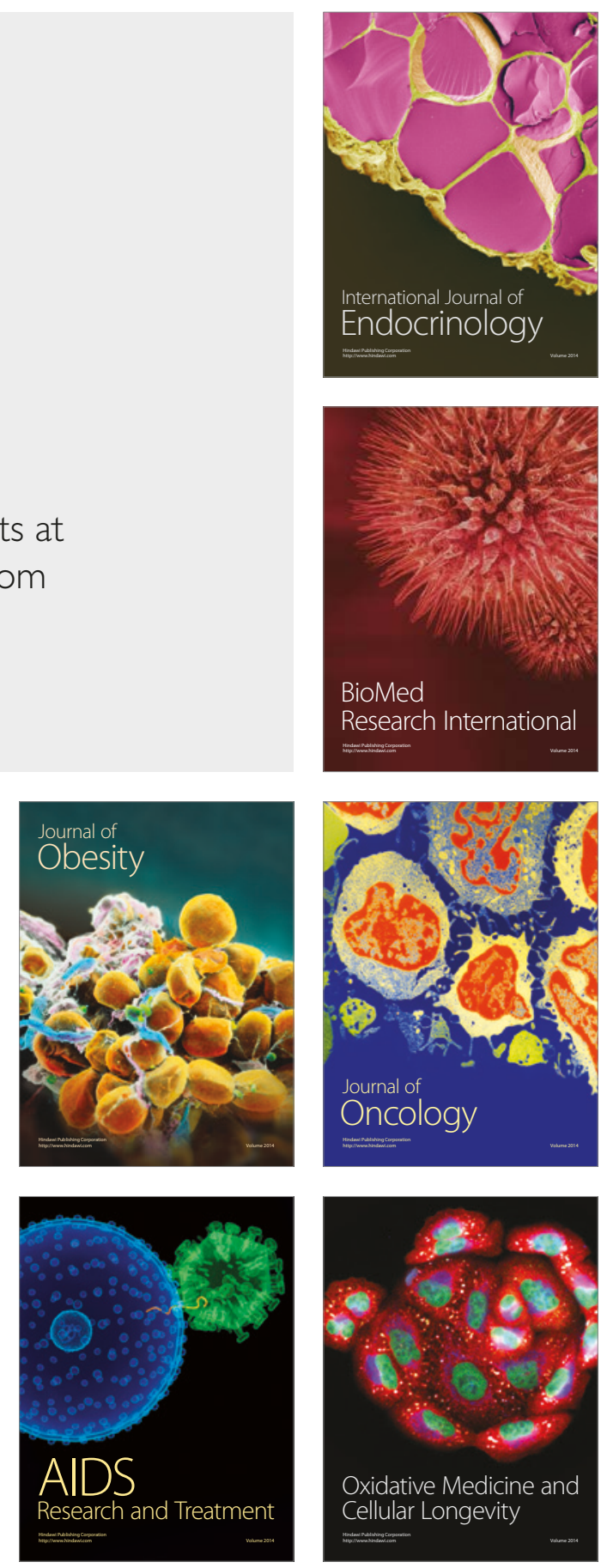